\title{
Characterization of SRM plumes with alumina particulate in subscale testing
}

\section{Fundamental outline and first results of the ESA-EMAP project}

\author{
Dominik Saile ${ }^{1}$ (1) - Dirk Allofs ${ }^{1} \cdot$ Viktor Kühl $^{1} \cdot$ Lars Steffens $^{1} \cdot$ Ali Gülhan ${ }^{1} \cdot$ Manfred Beversdorff $^{2}$ - Wolfgang Förster ${ }^{2}$. \\ Chris Willert $^{2} \cdot$ Stefania Carlotti $^{3} \cdot$ Filippo Maggi $^{3} \cdot$ Mattias Liljedahl $^{4} \cdot$ Niklas Wingborg $^{4} \cdot$ Tobias Langener $^{5}$. \\ Jeroen van den Eynde ${ }^{5}$
}

Received: 12 March 2020 / Revised: 29 July 2020 / Accepted: 13 October 2020 / Published online: 23 December 2020

(c) The Author(s) 2020

\begin{abstract}
The current paper provides an outline and first results of the ESA-EMAP project. This project pursues activities regarding the experimental modeling of alumina particulates in solid boosters (EMAP). The issue regards the particles residing in the atmosphere after the passage of a launch vehicle with solid rocket propulsion, which might contribute to local and overall ozone depletion. The question is to what extent since the particle size distribution left behind is essentially unclear. For this reason, the ESA-EMAP investigations focus on the characterization of the solid exhaust plume properties for well-defined combustion chamber conditions. Thus, details of the rocket motor assembly, of the developed solid propellant grains, and of first measurement results are provided. The paper presents technical findings concerning the rocket motors and reveals aspects to the feasibility of the applied measurement techniques.
\end{abstract}

Keywords Subscale solid rocket motor test $\cdot$ Propellant composition $\cdot$ Burn rate analysis $\cdot$ Hot jet $\cdot$ Exhaust plume $\cdot$ Particle formation · Particle size $\cdot$ Measurement methods for SRMs

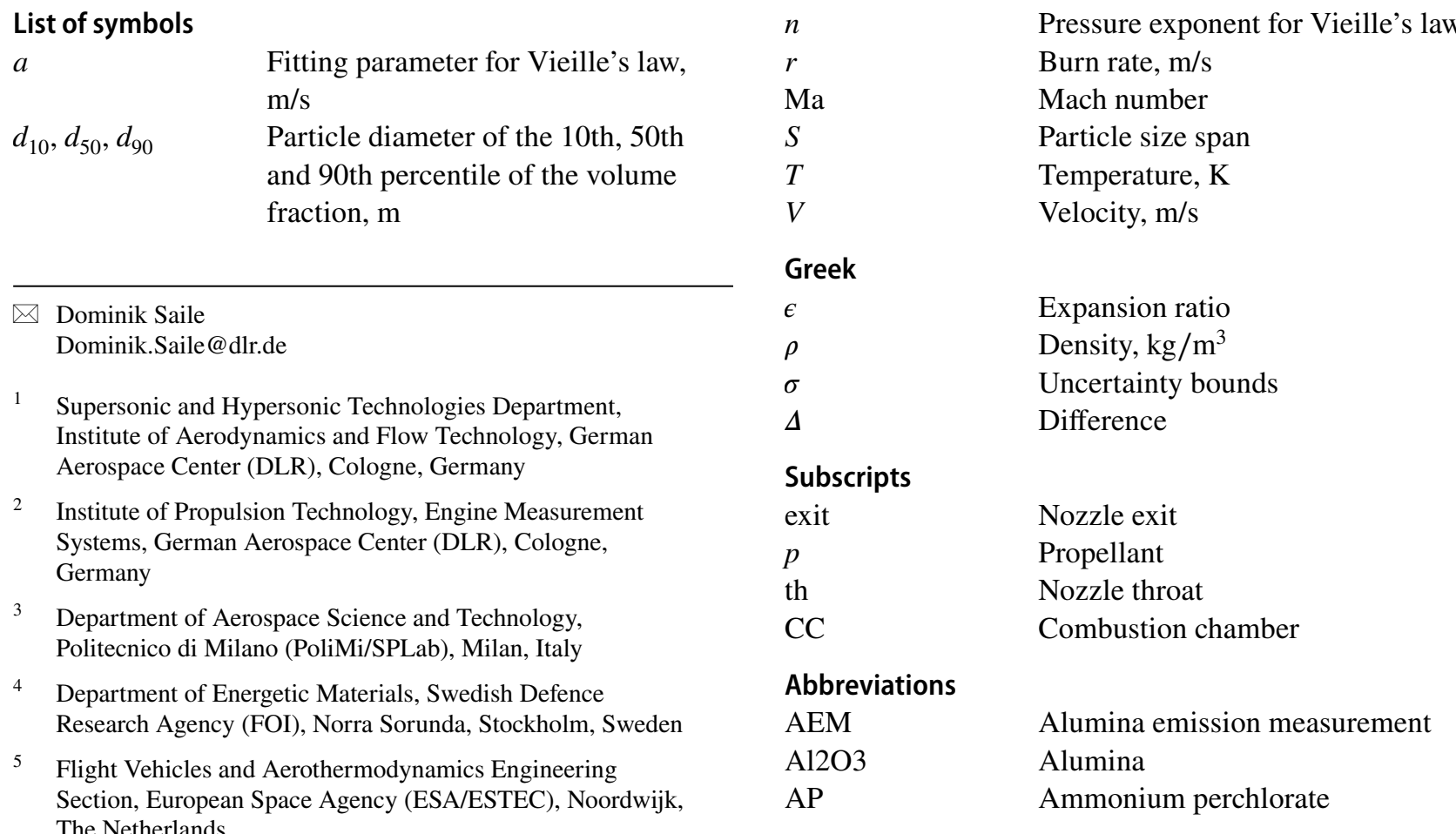




\begin{tabular}{|c|c|}
\hline APS & Aerodynamic particle sizer \\
\hline BATES & Ballistic test and evaluation system \\
\hline $\mathrm{CO}$ & Carbon monoxide \\
\hline CO-DLAS & $\begin{array}{l}\text { Carbon monoxide-based diode laser } \\
\text { absorption spectroscopy }\end{array}$ \\
\hline $\mathrm{CO} 2$ & Carbon dioxide \\
\hline DIPSD & $\begin{array}{l}\text { Direct image particle size } \\
\text { determination }\end{array}$ \\
\hline EMAP & $\begin{array}{l}\text { Experimental modeling of alumina } \\
\text { particulates in solid boosters }\end{array}$ \\
\hline ESA & European space agency \\
\hline $\mathrm{Ex} 1, \mathrm{Ex} 2, \mathrm{Ex} 3$ & $\begin{array}{l}\text { Nozzle expansion configuration } 1,2, \\
\text { and } 3\end{array}$ \\
\hline FTIR & $\begin{array}{l}\text { Fourier transform IR emission } \\
\text { spectroscopy }\end{array}$ \\
\hline FWHM & Full width at half maximum \\
\hline $\mathrm{HCl}$ & Hydrochloric acid \\
\hline HSS & High-speed schlieren \\
\hline НТРВ & Hydroxyl-terminated polybutadiene \\
\hline НTPB1814 & $\begin{array}{l}\text { HTPB-based propellant with } 18 \% \\
\text { aluminum }\end{array}$ \\
\hline НТРВ0514 & $\begin{array}{l}\text { HTPB-based propellant with } 5 \% \\
\text { aluminum }\end{array}$ \\
\hline НТРВ0014A12O3 & $\begin{array}{l}\text { HTPB-based propellant with } 5 \% \\
\text { alumina }\end{array}$ \\
\hline $\mathrm{H} 2 \mathrm{O}$ & Water \\
\hline IR & Infraed thermography \\
\hline K & Potassium \\
\hline L2F & Laser-2-focus \\
\hline MWI & Micro-wave interferometry \\
\hline $\mathrm{Na}$ & Natrium \\
\hline PEEK & Polyether ether ketone \\
\hline $\mathrm{P} 1, \mathrm{P} 2, \mathrm{P} 3$ & $\begin{array}{l}\text { Pressure level configuration } 1,2 \text {, anc } \\
3\end{array}$ \\
\hline PIV & Particle image velocimetry \\
\hline RPA & Rocket propulsion analysis tool \\
\hline RPC & Rocket plume collector \\
\hline SRM & Solid rocket motor \\
\hline TIC & Truncated ideal contour \\
\hline TMD & Theoretical maximum density \\
\hline $\mathrm{UV}-\mathrm{Vis}$ & $\begin{array}{l}\text { Emission spectroscopy in the ultra- } \\
\text { violet and visible spectral regions }\end{array}$ \\
\hline VMK & $\begin{array}{l}\text { Vertikale Messstrecke Köln/vertical } \\
\text { test section Cologne }\end{array}$ \\
\hline & Wind tunnel \\
\hline
\end{tabular}

\section{Introduction}

The ESA-EMAP project was initiated to pursue activities regarding the experimental modeling of alumina particulates in solid boosters. The main driver for the activities is related to the uncertainty and discrepancy of studies regarding the impact of the alumina particles emitted by solid rocket motors (SRMs) on the ozone depletion of the stratosphere. Heterogeneous reactions on the surface of alumina particles, in particular chlorine activation reactions, are considered as a significant mechanism potentially doubling the change in annually averaged total ozone attributed to the emission SRMs [1]. Of major concern is the particle size distribution. In models regarding the global ozone depletion, chlorine activation reaction is sensitive to the surface area fraction of the particles [2].

It is stated by Schmid et al. [1] that for small SRMs, the ozone loss due to reactions on alumina emissions is comparable to the ozone loss of the gas phase chlorine emissions alone. Ross et al. [3], on the other hand, found out that reactions on alumina have only an insignificant influence on stratospheric chemistry. The difference of this assessment is attributed to the difference of the measured alumina particle size distribution. The latter study describes that less than a few hundredths of a percent of the alumina mass resides in the smallest particle size mode, while Schmid et al. [1] found $8 \%$ of the total mass in submicron size range, which corresponds $37 \%$ of the total surface area.

The objective of the current study now is to shed light on the formation processes of alumina in solid propellant launcher. These activities take place in the frame of the CLEAN SPACE initiative by ESA, which has as overarching goal the reduction of environmental impacts of launch vehicles. To do so, it is necessary to quantify the actual emission induced by each launch. Thus, it is of importance to determine the plume conditions and its impact on the atmosphere. In particular, the formation and development process of alumina particulates and/or other aerosols, and aspects to its long-term presence in the atmosphere are of interest. Note that particles in the exhaust plume also lead to a variety of technical challenges for space transportation such as increased heat loads, contamination of system-relevant surfaces or to radio-frequency interference. Such effects are reported in Simmons [4], Goethert [5], Kinefuchi et al. [6].

In the frame of ESA-EMAP, the objectives are to characterize the exhaust plume as extensively as possible with respect to the exhaust gas, the exhaust particles and the heat flux. However, the study at hand must be seen as a first step for further publications. It provides an overview to the methods applied, the materials used, and the approach taken. Another focus is on the technical aspects of the development of the rocket motor and with respect to the measurement techniques. For the latter, it was always the question if the corresponding measurement technique can cope with the harsh measurement environment and capture the targeted data. Concerning the motor, some of these technical questions are listed below. These are the questions that will be addressed in the paper at hand. 
- Can the glow plug used for the ignition?

- Does the insulation material provide sufficient protection for the walls?

- Does the combustion chamber pressure evolve as predicted?

- Is tungsten suitable as material for the nozzles?

- Can PEEK be used as material for the heat flux measurements in the base region?

- Are the measurement methods applicable as intended?

- Is the reciprocal interference of various measurement methods limited and as predicted?

\section{Methods: test environment}

In the following, the test environment consisting of the 'Vertical test section Cologne' (VMK), the rocket motor, and as part of the rocket motor, the solid propellant grains are described.

\subsection{Vertical test section Cologne (VMK)}

The experiments are executed in the 'Vertical test section Cologne' (VMK). VMK [7-9] is a blow-down type wind tunnel featuring a vertical and free test section for tests in the subsonic to supersonic range starting from Mach 0.5 up to 3.2. The current experiments were conducted with a subsonic nozzle featuring an exit diameter of $340 \mathrm{~mm}$.

\subsection{Rocket motor}

A rocket motor was used for the execution of the experiments. This motor is shown in Fig. 1 and, as it can be seen, it is integrated via an upstream support (1) in the subsonic wind tunnel nozzle (2). The rocket motor consists of the main casing of the motor (3), a bottom plate (4), a nozzle block (5a-c) and a base plate (6). A zoom of the nozzle block is provided in Fig. 2. For the main tests, end burner grains (7) as introduced in Sect. 2.3 are used. In this case, the void in the motor is filled with a dummy propellant (8). A hull (9) is put over the rocket motor and the gap between the motor and the hull is used for harnessing. For the case at hand, this is only the glow plug (10) for the ignition of the propellants. For the precursor measurement calibration tests, commercially available BATES grains are used.

The main casing (3) is made of inconel 718. For one part of the nozzle block $(5 a+5 b)$, molybdenum is used while the nozzles themselves $(5 \mathrm{c})$ are made of tungsten. The nozzle block is the assembly group which is the most exposed to heat and pressure loads. One of the questions was how these components withstand the imposed loads. A discussion of which is part of the results in Sect. 4.1.

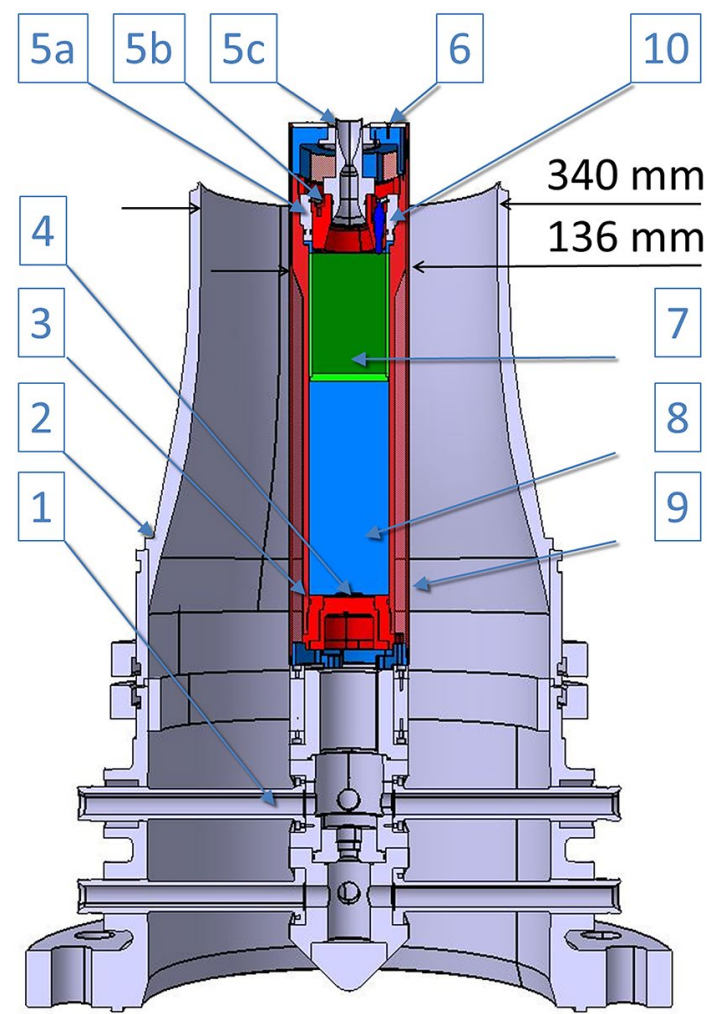

Fig. 1 Sketch of the wind tunnel model with rocket motor

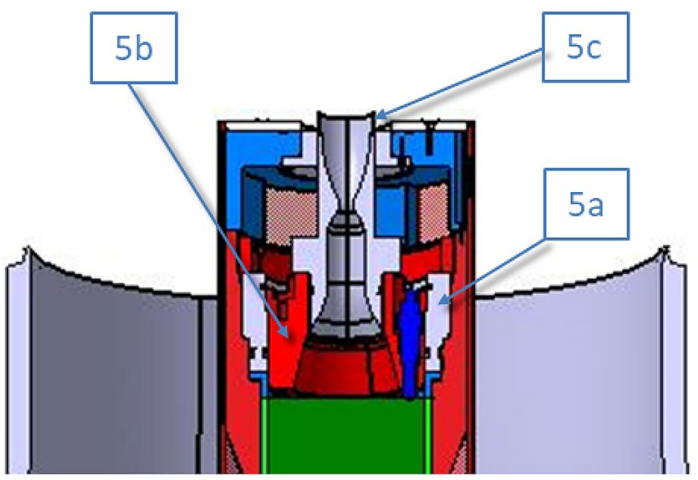

Fig. 2 Close-up of the nozzle block of the wind tunnel model

Another objective was to take measurements at specified nozzle exit planes for flight-realistic chamber pressure levels and flight-realistic expansion ratios. For this purpose, the P120C booster of Ariane 6 was selected as reference. It operates at a combustion chamber pressure level of about $6 \mathrm{MPa}$, while the nozzle is designed for an exit Mach number of about 3.4. Further, the boosters used by Ariane 5 operate at comparable conditions. In that sense, the first stage rocket motor Zefiro 23 of VEGA differs with respect both key figures. The nominal combustion chamber pressure level 
and exit Mach number is at 9.5 MPa and about 3.6 $(\epsilon=25)$, respectively.

To be similar with the reference case, corresponding nozzles were developed. In total, nine different nozzles with different nozzle contours were manufactured with three different throat diameters and three different expansion ratios. In the order of ascending chamber pressure levels, the throat diameters are $d_{\mathrm{th}}=7.75,6.57$ and $5.74 \mathrm{~mm}$, which correspond to pressure level P3, P2, and $\mathrm{P} 1$, respectively. Depending on the propellant, the pressure levels actually refer to differing pressures. For pressure level P1, the predicted combustion chamber pressure is $2.9,3.0$ and $2.3 \mathrm{MPa}$ for HTPB0514, HTPB0014Al2O3, and HTPB1814, respectively. For pressure level P2, it is 5.1, 5.3 and 4.0 MPa, respectively. For pressure level P3, only tests with HTPB 1814 were executed for which a pressure of $6.2 \mathrm{MPa}$ was determined. The three expansion ratios $\epsilon$ are 14.4, 2.1, and 1.0, which are equivalent to an exit Mach number of 3.23, 2.1 and about 1, respectively. These expansion configurations are denoted with Ex1, Ex2, and Ex3, respectively. They were selected with the objective to gather data for a configuration similar to flight of the conditions at the nozzle throat $(\epsilon=1.0)$, at the nozzle exit $(\epsilon=14.4)$ and at a location in between $(\epsilon=2.1)$. An overview of selected conditions in the combustion chamber, the nozzle throat and at the nozzle exit is provided in Table 1.

Note that the nozzles with the largest expansion ratio are used as baseline. In other words, the contours of the various Mach numbers (for one throat diameter) are essentially the same except for the fact that they are truncated at the locations to reach corresponding Mach numbers. The nozzle type corresponds to a truncated ideal contour (TIC) nozzle designed by means of the method of characteristics [11] without compensation of the boundary layer displacement. It was determined by means of the 'RPA - rocket propulsion analysis' software [10]. The exit angle for the nozzle with the largest expansion ratio is $\leq 0.5^{\circ}$.

Despite being different with respect to the contour, the outer silhouette of the wind tunnel model remains the same for all investigated nozzle configurations. In other words, similarity is given with respect to the outer geometry independently of the internal contour of the nozzle. This is visualized in Fig. 3. Apart from the geometric similarity, this approach is also advantageous for the setup of the measurement systems: the region of interest is fixed at a location downstream from the nozzle exit and the measurement equipment does not require a readjustment when changing the nozzle configuration.

The main focus of the study is not necessarily on the interaction phenomena between the ambient flow and the jet flow with focus on the buffeting issues of rockets such as investigated in previous works [12-16]. This would also be difficult taking into account the influence of the protection shield for the RPC probe as introduced in Sect. 3, which significantly influences - when used - the near-wake flow. Instead the overarching study objective lays on the exhaust plume, and for this study in particular, on the rocket motor and the feasibility of measurement techniques. For this reason, the relatively large diameter/area ratio between the nozzle exit and the wind tunnel model appears justified.

Last, a measurement matrix is provided in Table 2. It already contains results with respect to the clogging of the nozzle (end diam. and $\Delta$ diam.), which are elaborated below. Here, it shall provide the input conditions for testing such as the ambient Mach number (Ma) of the wind tunnel (WT), if the protective shield (shield) is applied, the batch ID of the propellant, the percentage and type of supplemented particles (suppl.), the initial diameter of the nozzle throat (initial diam.) and the run ID.

\subsection{Solid propellant grains}

The solid propellant grains are of the end burning type. The idea behind was that end burners typically satisfy the requirement for a constant pressure evolution over time. The intention of which is to aim for constant conditions for all measurement techniques over one run.

In frame of the project, three different solid propellants types were developed:

- HTPB 1814 with 18\% aluminum and 14\% HTPB,

- HTPB0514 with 5\% aluminum and 14\% HTPB and

- HTPB0014Al2O3 with 14\% HTPB and with 5\% $\mathrm{Al}_{2} \mathrm{O}_{3}$ as inert filler.

Note that HTPB stands for hydroxyl-terminated polybutadiene. For the case at hand, HTPB 1814 is intended for the investigation of a realistic booster plume comparable to the Ariane 5 configuration, HTPB0514 is less smoky and is being used for investigations where optical transparency is required (e.g. PIV), and HTPB0014Al2O3 is intended for the validation of the particle size measurement approaches. Apart from $\mathrm{Al}_{2} \mathrm{O}_{3}$, the propellants developed are based on conventional ingredients such as ammonium perchlorate (AP) embedded in a HTPB based binder, similarly as used in Ariane 5 and Vega.

Turning shortly to the subject of inert particles, the integrity of which cannot be guaranteed. The calculated combustion chamber temperature for the propellant with alumina is in the range of $2750 \mathrm{~K}$, while the melting point of alumina is found at $2345 \mathrm{~K}$. In other words, melting, coalescence and/or agglomeration of the alumina particles cannot be excluded 


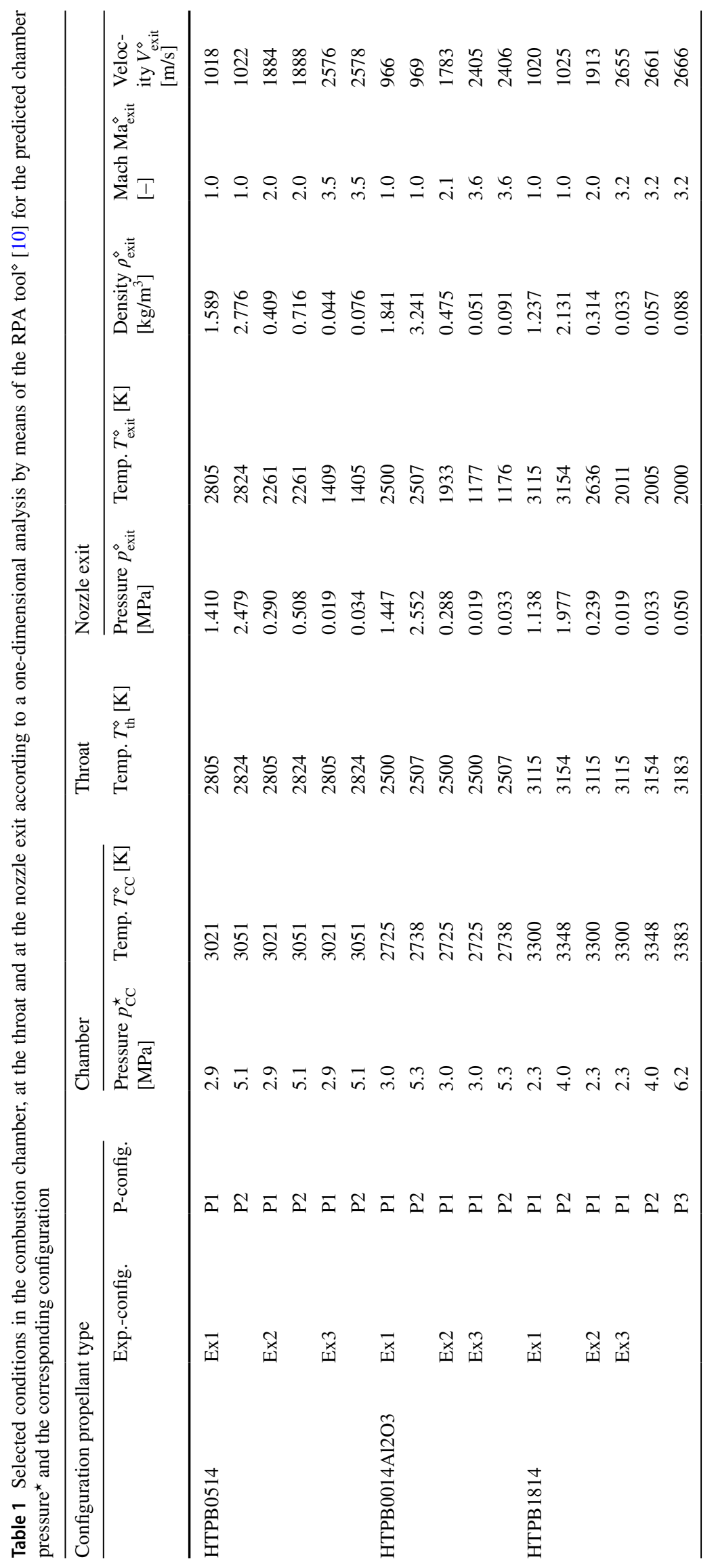



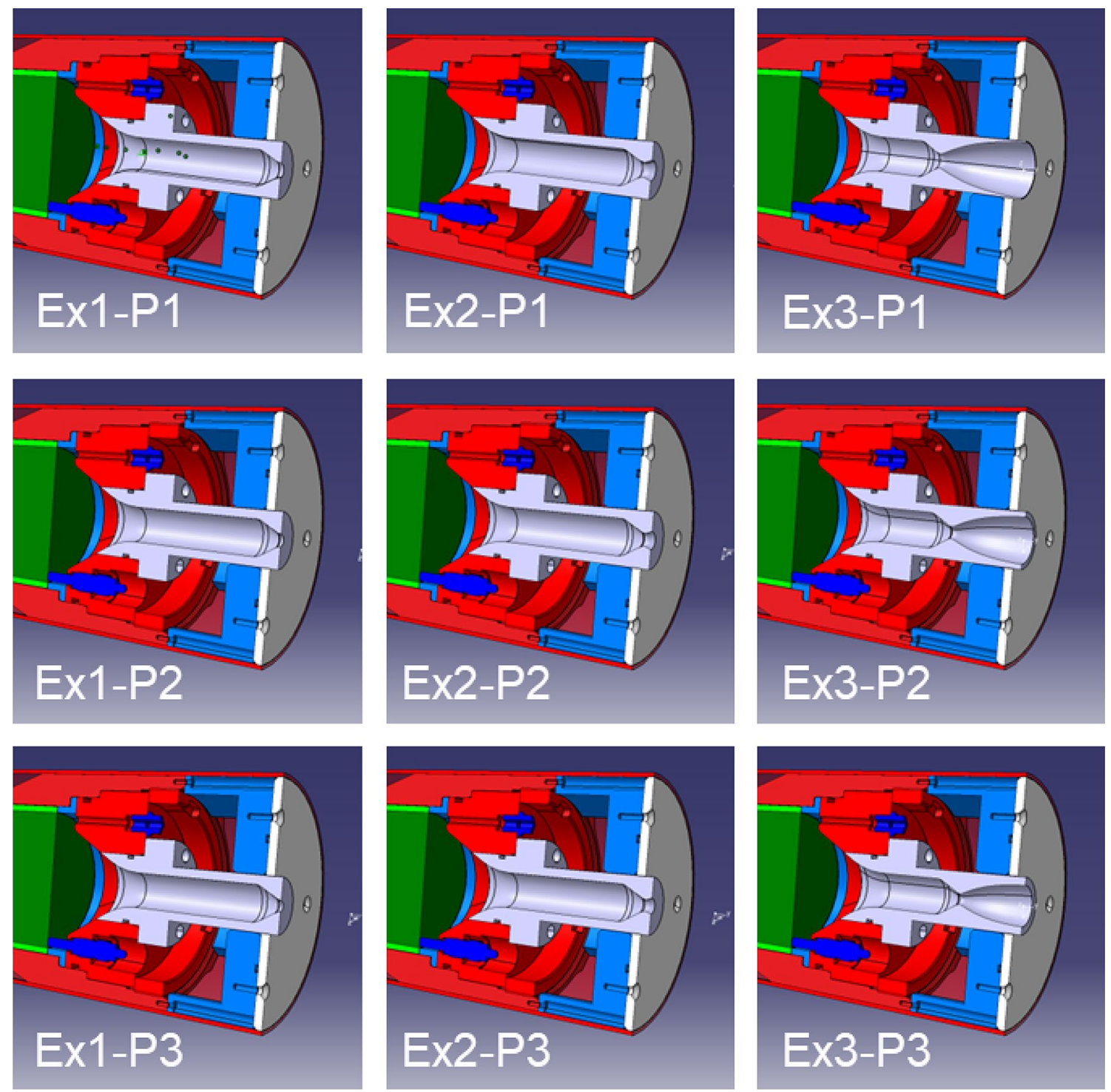

Fig. 3 Nozzle configurations under investigation and nozzle length with respect to the base plate

as possible particle formation/alteration processes. Initially, magnesia featuring a higher melting temperature was considered as inert filler. However, further investigations and experiments in the frame of ESA-EMAP showed that magnesia is acting as a scavenger, by partially decomposing to remove chlorine. The resulting propellant exhibited a high pressure exponent, and in combination with a uncertainty level of the propellant, which caused the expected range of operations to be too far from rocket specifications, the usage of magnesia was discarded in favor for the alumina. In fact, alumina is a one of the combustion products of standard solid rocket motors. Nevertheless, to be clear, the inert aspect of alumina particles is still to be proven.
The composition of the HTPB based binder is shown in Table 3. The binder composition is selected to be similar to what is used in state of the art solid rocket propellants. Two different batches of HTPB were used; HTPB R45HTLO from Cray Valley (for propellant batch no. G180243) and HTPB Polyvest from Evonik (for propellant batch no. G180245). The HTPBs have previously been evaluated and are expected to produce materials with very similar behavior. The reason for using two different batches was a shortage of material of the same batch for all the casts. It was decided to use HTPB Polyvest in one of the HTPB0514-batches since that composition was produced in duplicate. The batch of HTPB R45HTLO 
Table 2 Measurement matrix including the throat diameter before (initial diam.) and after (end diam.) a hot firing test

\begin{tabular}{|c|c|c|c|c|c|c|c|c|}
\hline \multirow{2}{*}{$\begin{array}{l}\text { WT } \\
\text { Ma }\end{array}$} & \multicolumn{7}{|c|}{ Wind tunnel (WT) model } & \multirow[b]{2}{*}{ Run ID } \\
\hline & Shield & Nozzle ID & Batch ID & Suppl. & $\begin{array}{l}\text { Initial diam. } \\
{[\mathrm{mm}]}\end{array}$ & End diam. [mm] & $\Delta$ Diam. $[\mathrm{mm}]$ & \\
\hline 0.77 & Yes & Ex1-P1 & 243 & $5 \% \mathrm{Al}$ & 7.75 & 6.50 & $\sim 1.3$ & Run015-V33-End \\
\hline 0.61 & Yes & Ex2-P1 & 243 & $5 \% \mathrm{Al}$ & 7.75 & 6.62 & $\sim 1.1$ & Run016-V32-End \\
\hline 0.84 & Yes & Ex3-P1 & 243 & $5 \% \mathrm{Al}$ & 7.75 & 6.15 & $\sim 1.6$ & Run014-V31-End \\
\hline 0.58 & Yes & Ex1-P2 & 243 & $5 \% \mathrm{Al}$ & 6.56 & 5.47 & $\sim 1.1$ & Run023-V12-End \\
\hline 0.59 & Yes & Ex3-P2 & 243 & $5 \% \mathrm{Al}$ & 6.56 & 5.60 & $\sim 1.0$ & Run024-V10-End \\
\hline 0.50 & No & Ex1-P1 & 245 & $5 \% \mathrm{Al}$ & 7.75 & 6.56 & $\sim 1.2$ & Run010-V01-End \\
\hline 0.50 & No & Ex2-P1 & 245 & $5 \% \mathrm{Al}$ & 7.75 & 6.16 & $\sim 1.6$ & Run012-V29-End \\
\hline 0.60 & Yes & Ex3-P1 & 245 & $5 \% \mathrm{Al}$ & 7.75 & 6.24 & $\sim 1.5$ & Run017-V30-End \\
\hline 0.50 & No & Ex1-P2 & 245 & $5 \% \mathrm{Al}$ & 6.56 & 5.60 & $\sim 1.0$ & Run011-V02-End \\
\hline 0.81 & No & Ex2-P2 & 245 & $5 \% \mathrm{Al}$ & 6.56 & 5.07 & $\sim 1.5$ & Run013-V04-End \\
\hline 0.62 & No & Ex3-P2 & 245 & $5 \% \mathrm{Al}$ & 6.56 & 5.40 & $\sim 1.2$ & Run031-V06-End \\
\hline 0.58 & Yes & Ex1-P1 & 244 & $5 \% \mathrm{Al}_{2} \mathrm{O}_{3}$ & 7.75 & 7.62 & $\sim 0.1$ & Run019-V35-End \\
\hline 0.63 & No & Ex2-P1 & 244 & $5 \% \mathrm{Al}_{2} \mathrm{O}_{3}$ & 7.75 & 7.50 & $\sim 0.3$ & Run018-V34-End \\
\hline 0.59 & Yes & Ex3-P1 & 244 & $5 \% \mathrm{Al}_{2} \mathrm{O}_{3}$ & 7.75 & 7.51 & $\sim 0.2$ & Run020-V36-End \\
\hline 0.59 & Yes & Ex1-P2 & 244 & $5 \% \mathrm{Al}_{2} \mathrm{O}_{3}$ & 6.56 & 6.47 & $\sim 0.1$ & Run021-V19-End \\
\hline 0.58 & Yes & Ex3-P2 & 244 & $5 \% \mathrm{Al}_{2} \mathrm{O}_{3}$ & 6.56 & 6.48 & $\sim 0.1$ & Run022-V17-End \\
\hline 0.60 & Yes & Ex1-P1 & 242 & $18 \% \mathrm{Al}$ & 7.75 & 7.37 & $\sim 0.4$ & Run025-V37-End \\
\hline 0.59 & Yes & Ex2-P1 & 242 & $18 \% \mathrm{Al}$ & 7.75 & 7.34 & $\sim 0.4$ & Run029-V39-End \\
\hline 0.59 & Yes & Ex3-P1 & 242 & $18 \% \mathrm{Al}$ & 7.75 & 6.91 & $\sim 0.8$ & Run026-V38-End \\
\hline 0.58 & Yes & Ex1-P2 & 242 & $18 \% \mathrm{Al}$ & 6.56 & 6.43 & $\sim 0.1$ & Run027-V26-End \\
\hline 0.59 & Yes & Ex3-P2 & 242 & $18 \% \mathrm{Al}$ & 6.56 & 5.92 & $\sim 0.6$ & Run028-V23-End \\
\hline 0.58 & Yes & Ex3-P3 & 242 & $18 \% \mathrm{Al}$ & 5.74 & 5.20 & $\sim 0.5$ & Run030-V25-End \\
\hline
\end{tabular}

Further, table lists the ambient Mach number (Ma), if the protective shield (shield) is applied, the batch ID of the propellant, the percentage and type of supplemented particles (suppl.), the nozzle throat diameter difference ( $\Delta$ diam.) before and after test, and the run ID

Table 3 HTPB binder composition (in parts per 100 parts of rubber, phr), with $\mathrm{NCO} / \mathrm{OH}$ ratio of 0.8

\begin{tabular}{lll}
\hline Chemical & Amount (phr) & Comment \\
\hline $\begin{array}{l}\text { HTPB R45HTLO or } \\
\text { HTPB Polyvest }\end{array}$ & 100 & Pre-polymer \\
BKF & 1.5 & \\
DOA & 25 & Antioxidant \\
TEPAN & 1 & Plasticizer \\
Desmodur W & 8.38 (R45HTLO) or 8.97 & Curing agent \\
& (polyvest) & \\
\hline
\end{tabular}

used has, according to the Cray Valley certificate of analysis, an $\mathrm{OH}$-functionality of $0.80 \mathrm{mmol} / \mathrm{g}$. The batch of HTPB Polyvest used has, according to the test report from Evonik, a hydroxyl number of $48 \mathrm{mg} \mathrm{KOH} / \mathrm{g}$. A NCO/OHratio of 0.8 was selected and the amount of Desmodur W needed was calculated to be $8.38 \mathrm{phr}$ for the HTPB R45HTLO binder and $8.97 \mathrm{phr}$ for the HTPB Polyvest binder.
Two brands of ammonium perchlorate were used. The first brand, from Switzerland Elektrochemie Turgi, type AMZ, with suitable particle size and morphology, was used as received. The second brand, from Trona, USA, type A, was grinded using a Sturtevant 4 inch Micronizer jet mill. Afterward, the particle size and distribution were measured using a Malvern Mastersizer 2000. The particle size was reported for the 10th, 50th and 90th percentile of the volume fraction; low 10\%, 50\% and high 10\% (shown as $d_{10}, d_{50}$ and $d_{90}$ ) and the particle size span $\mathrm{S}$ was calculated as given in Eq. 1. As a result, the measurement revealed a particle size of $d_{50}=168 \mu \mathrm{m}$ and a particle size span of $S=1.1$ for the AMZ (used as received). The Trona jet milled AP featured $d_{50}=7 \mu \mathrm{m}$ and $S=1.4$.

$S=\frac{d_{90}-d_{10}}{d_{50}}$.

Since the measurements focus on the particles in the exhaust jet, the initial particle size of aluminum and alumina, meaning before being released and possibly burned (aluminum) 
in the combustion chamber, shall also be provided hereafter. For the (supposedly) inert filler, the alumina powder Amperit 740.065 by H.C. Starck was used and, for the other propellants, aluminum powder was added to the propellant. The diameter of alumina at a volume fraction 10\%, 50\% and $90 \%$ is $\left[d_{10}, d_{50}, d_{90}\right]=[\min .11,19-23$, max.40] $\mu \mathrm{m}$. The size span is then in the range between $S=1.3$ and 1.5. The diameter of aluminum at volume fraction of a $50 \%$ is $d_{50}=16.5 \mu \mathrm{m}$ with a corresponding size span of $\mathrm{S}=1.2$.

Note that the alumina size distribution was selected to be approximately consistent with the alumina size distribution found in the exhaust plume of the boosters of Ariane 5 [17], which is a typical particle size distribution for a large engine. A corresponding correlation showing the mean alumina particle size as function of the engine scale can be found in Hermsen [18], Simmons [4]. There, the property of the engine scale is used as a measure to capture the magnitude of the particle acceleration in the nozzle.

Mixing and casting was executed under vacuum according to a predefined procedure. Then, all batches were cured at $70{ }^{\circ} \mathrm{C}$ for 5 days. The respective propellant composition are shown in Table 4. The volume fraction filler was between 73 and $74 \%$. As a last step, an insulation consisting of HTPB, carbon black and BKF cured with Desmodur W was applied at the bottom and on the side walls (along the circumference) of the propellants. The weight of each grain was, depending on the propellant grain type, in the range between about $850 \mathrm{~g}$ and $890 \mathrm{~g}$.

All manufactured grains had densities within $1 \%$ of theoretical maximum density (TMD). The corresponding densities are shown in Table 5. This table also contains data of strand burner tests for the determination of the burn rates of the propellants. For that purpose, data correlation with data from the strand burner tests has been performed using the classical Vieille's law $r_{b}=a p_{\mathrm{CC}}^{n}$, where $r_{b}$ is the burning rate, $\mathrm{a}$ and $\mathrm{n}$ are fitting parameters, and $\mathrm{p}$ is the pressure. Generally, the uncertainty bounds for a and $\mathrm{n}$ are $\sigma_{a}<0.36$ and $\sigma_{n}<0.42$, respectively.

\section{Methods: measurement techniques}

As introduced above, VMK is a blow-down type wind tunnel facility with an open test section. The combination of having the wind tunnel nozzle vertically aligned and featuring an open test section is advantageous for the current tests since it offers the space which is required for the highly instrumented experiments in the frame of ESA-EMAP. An
Table 4 Propellant composition

\begin{tabular}{llll}
\hline Component & HTPB1814 (\%) & HTPB0514 (\%) & $\begin{array}{l}\text { HTP- } \\
\text { B0014A12O3 } \\
(\%)\end{array}$ \\
\hline HTPB binder & 14 & 14 & 14 \\
AP AMZ (coarse) & 53.3 & 56.1 & 55.2 \\
AP jet milled (fine) & 14.2 & 24.4 & 25.3 \\
$\mathrm{Al}$ & 18 & 5 & 0 \\
$\mathrm{Al}_{2} \mathrm{O}_{3}$ & 0 & 0 & 5 \\
$\mathrm{Fe}_{2} \mathrm{O}_{3}$ & 0.5 & 0.5 & 0.5 \\
\hline
\end{tabular}

Table 5 Propellant properties and burn rates; propellant density $\rho_{p}$ was determined using He-pycnometer

\begin{tabular}{lllll}
\hline Prop. type & Density $\rho_{p}\left[\mathrm{~g} / \mathrm{cm}^{3}\right]$ & $a$ & $n$ & Batch no. \\
\hline HTPB1814 & 1.7747 & 2.196 & 0.399 & $\mathrm{G} 180242$ \\
HTPB0514 & 1.7223 & 2.473 & 0.420 & $\mathrm{G} 180243$ \\
HTPB0514 & 1.7163 & 2.504 & 0.415 & $\mathrm{G} 180245$ \\
HTPB0014A12O3 & 1.7365 & 2.478 & 0.415 & $\mathrm{G} 180244$ \\
\hline
\end{tabular}

overview of the measurement techniques and targeted quantities is given in Table 6.

Obviously, the application of the measurement techniques is a trade-off between multiple variables. In literature, further measurement techniques can be found such as given in an overview in Simmons [4]. There, Raman scattering, laser-induced fluorescence, coherent anti-Stokes scattering, crossed-beam correlations, Rayleigh scattering and tagging are referenced as beam-induced plume diagnostics to reveal data about the plume. In particular with respect to particles, the application of mie scattering, mie extinction, laser backscatter, and diffusion correlation spectroscopy are suggested. An elaborate overview to aerosol measurements in general can be found in [19].

The trade-off for the measurement techniques at hand is driven by applicability, by availability and by the requested quantities to be measured. In fact, some of the initially investigated measurement techniques were omitted as a result of precursor instrument qualification tests. For instance, absorption-based spectroscopy, carbon monoxide-based diode laser absorption spectroscopy (CO-DLAS), and micro-wave interferometry (MWI) were excluded due to issues regarding the availability of an appropriate light source, issues induced due to the beam refraction through the plume, and issues resulting from vibrational disturbances 
Table 6 Overview of the measurement techniques and targeted quantities

\begin{tabular}{|c|c|c|c|c|c|c|c|c|}
\hline \multirow[t]{2}{*}{ Method } & \multicolumn{3}{|c|}{ Particle } & \multicolumn{5}{|l|}{ Flow } \\
\hline & Size & Temp. & Vel. & Temp. & Vel. & Press. & Spec. & other \\
\hline FTIR & & (x) & & $\mathrm{x}$ & & & $\mathrm{x}$ & \\
\hline UV-Vis & & $\mathrm{x}$ & & & & & $\mathrm{x}$ & \\
\hline AEM & & $\mathrm{x}$ & & & & & & \\
\hline PIV & & & $\mathrm{x}$ & & & & & \\
\hline HSS & & & & & & & & $\mathrm{x}$ \\
\hline DIPSD & (x) & & $(\mathrm{x})$ & & & & & \\
\hline L2F & & & $\mathrm{x}$ & & & & & \\
\hline APS & $\mathrm{x}$ & & & & & & & \\
\hline RPC & $\mathrm{x}$ & & & & & & & \\
\hline Press. trans. & & & & & & $\mathrm{x}$ & & \\
\hline Gardon gauge & & & & & & & & $\mathrm{x}$ \\
\hline IR & & & & $\mathrm{x}$ & & & & (x) \\
\hline
\end{tabular}

The quantities marked with an $\mathrm{x}$ can be determined; for the one in brackets (x), it is uncertain. The 'other' column refers to density gradients, the radiative heat flux and the base plate temperature for PIV, Gardon gauge and IR, respectively during testing, respectively. In particular with respect to the particle measurement, there was a desire to extract particles directly from exhaust plume, which is executed with the newly developed RPC (Sect. 4.2.10). For particles farther downstream, a well-established approach was taken using the APS (Sect. 4.2.7).

The image in Fig. 4 provides a top view on the measurement setup in VMK. It shows the inside of VMK with the wind tunnel model integrated in the wind tunnel nozzle. The wind tunnel model mimics the base region of a launch vehicle. To simulate a flight-realistic exhaust plume, a solid rocket motor is integrated in the base model. The rocket motor expels the hot jet in the upward direction through a nozzle. Simultaneously, the wind tunnel provides an ambient flow at Mach 0.6 for most of the experiments. In other words, a co-flow between a cold ambient flow and a hot solid propellant exhaust jet is present.

For this reason, the wind tunnel model is surrounded with measurement equipment. Just downstream from the nozzle exit of the rocket motor, one can find the 'rocket plume collector' (RPC) [20]. The RPC is used to collect particles for the determination of the particle size distribution. It is protected from the hot exhaust gas by a protective shield, which only opens for $0.5 \mathrm{~s}$ during each run. The aerodynamic
Fig. 4 Top view on the wind tunnel and measurement setup

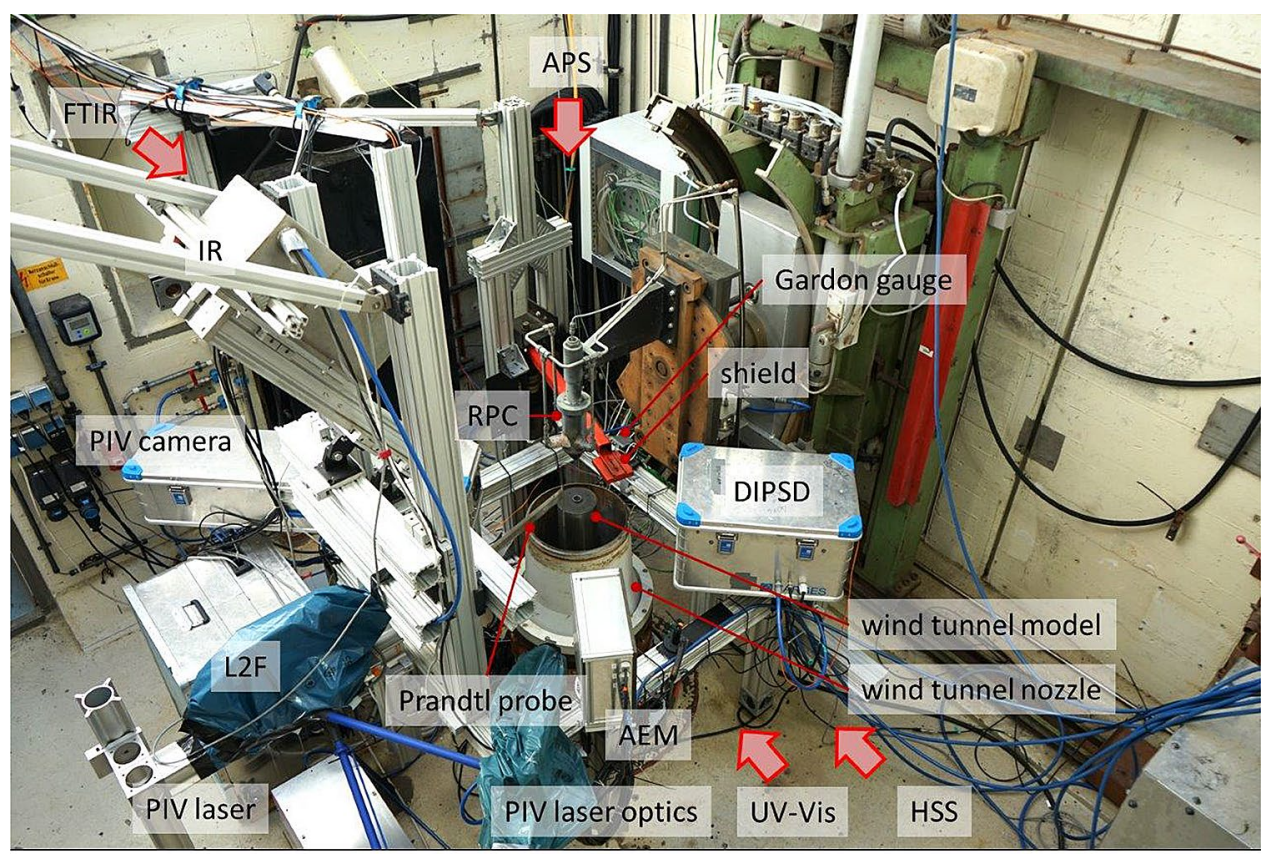


particle sizer (APS) is even farther downstream and serves the same purpose by means of the scattering intensity of light on particles and by aerodynamic measurements. The heat flux is captured with two different methods: first, an infrared camera (IR) acquires the temperature evolution of the base, and second, a Gardon gauge points at the rocket exhaust plume to collect data of its heat flux radiation. The temperature of the rocket exhaust plume itself is assessed with spectroscopic measurements. Measurements by means of Fourier-transform infrared spectroscopy (FTIR) and by spectroscopy in the ultraviolet-visible range (UV-Vis) are conducted. Moreover, in the frame of this project, AEM (alumina emission measurement) was adapted to the given requirements. The idea of AEM is to determine the phase state of the alumina particles inside the plume using their thermal emission. These spectroscopic methods also provide information of the various species in the plume. For particle image velocimetry (PIV), a pulsed laser system illuminates the particles in the rocket exhaust plume. Cameras on either side perpendicular to the laser sheet capture the scattered light. The PIV camera targets as region of interest about one to two shock cells of the jet shock train. The camera for DIPSD (direct imaging particle size determination) is focused on a very small range (order of $4 \mathrm{~mm}$ ) of the exhaust plume. On the one hand, the intention of DIPSD is to directly gather data of the particle size by imaging glare points. On the other hand, it might also be used to deduce information about the velocity by cross-correlating particle images. The results of the velocimetry methods can then be cross-checked with highly accurate laser-2-focus (L2F) measurements. High-speed schlieren (HSS) imaging concludes the list of measurement techniques for the exhaust plume. It is used to determine the density gradient field, and in particular, to visualize expansion and shock patterns in the flow field. The conditions of the rocket motor are monitored with two pressure sensors, and the ambient Mach number with a pitot-static/Prandtl tube. Note that all measurement equipment is put in boxes or wrapped to protect it from the corrosive exhaust plumes.

\section{Results and discussion}

In the next section, the experiences with the rocket motor are discussed. Then, in Sect. 4.2, the measurement results are provided. These results are preliminary and not yet fully post-processed since, in the paper at hand, the focus lays on feasibility aspects. Further details will be presented in a follow-up publication.

\subsection{Experiences regarding the rocket motor and the protective shield}

This section discusses the experiences made with the current rocket motor such as with the glow plug, with the insulation, with the tungsten nozzle, and with the base plate.

Over the course of various measurement campaigns in VMK, the glow plug has replaced the pyrotechnic initiator as igniter for most test purposes at hand. During the setup procedure, the propellant is installed in such a way that it is pressed against the surface of the glow plug. The ignition is then triggered by supplying the glow plug with a sufficient amount of electrical energy. Ignition with the glow plug is safe, repeatable and reliable. It is safe since it evades the handling of sensitive pyrotechnic initiators. It is repeatable since the ignition takes place at about the same location. In other words, the ignition is not dependent on the location of the pyrotechnic initiator, which has usually been threaded from the top through nozzle into the combustion chamber. The glow plug is at a fixed location and, in contrast to the threaded pyrotechnic initiator, it cannot be moved due to aerodynamic forces imposed by the ambient wind tunnel flow. Using glow plugs, the number of misfires in the wind tunnel tests essentially dropped to zero.

As presented in Sect. 2.3, insulation was applied on the side and bottom wall of the propellant grain. An open question was whether the insulation withstands the heat load throughout tests. For that reason, the rocket motor was protected by an extra thermal protection layer consisting of a phenolic liner. Figure 6 shows both components after a representative test. It can be seen that both components barely suffer from the heat load and can be considered as intact. The carbon insulation rubber coat, which contained the propellant, is obviously deformed due to the heat, however it did not disintegrate. This is even more so for the phenolic liner, which even kept its characteristic original brownish color, meaning noteworthy pyrolysis of the material did not take place.

The behavior of the nozzle was the next open question in context of the behavior of rocket motor. In previous works, good experiences were gained with nozzles made of steel and a graphite nozzle inlet. However, since graphite is a brittle material, the surface of a graphite inlet suffers over time. To avoid that, it was decided to use tungsten as nozzle material for the tests at hand. Figure 7 shows one of the nozzles after some tests for which a dye penetrant dye inspection was carried out to find possible hairline fractures. As it can be seen by the pinkish color of the retraction dye, the tungsten nozzle actually features a hairline fracture upstream from 
the nozzle exit. It is assumed that the fractures are caused by thermal shocks. However, the fractures do not seem to penetrate the nozzle completely. During the tests, no leakage through the walls was observed neither in high-speed schlieren recordings nor in the particle image velocimetry recordings. Moreover, no residues of the plume were found on the nozzle after the tests. Despite these cracks, the tungsten nozzle itself appeared to be a good choice since the inner contour of the nozzle was maintained over all tests.

In the environment directly outside the combustion chamber is the base plate. The heat flux on the base plate is a quantity of interest for real flight configurations since, on the one hand, it prescribes the required insulation in the base region, and on the other hand, not much data is available for that. Thus, it was considered to measure the heat flux on a base plate made of PEEK by means of IR thermography. PEEK offers the advantage that the material properties (e.g. emissivity) are well-know and an adiabatic boundary condition can be assumed on the backside of the base plate due to the good insulating properties. However, as it can be seen in Fig. 8, the PEEK material showed to be not suitable for that purpose. Due to the high heat loads it started to decompose. Note that PEEK features a melting temperature of $616 \mathrm{~K}$. For the rest of the measurement campaign, black-colored aluminium was used.

In total, 26 successful hot firing tests were executed with the rocket motor. All of them used the same nozzle block of which one of the molybdenum parts failed during the 27 th experiment. The corresponding part is marked as $5 \mathrm{a}$ in Figs. 1 and 9 shows an image of the damage after the last experiment.

In detail, this image depicts the top view into the rocket motor while it misses two parts of the nozzle block and the base plate (5b, 5c and 6 in Fig. 1, respectively). Further, the damage is divided into two sections: Sect. 1 relates to a cut out section and Sect. 2 marks the remaining original section. The division into the two sections corresponds exactly to the form of the circlip (Seeger ring) used to hold the other two parts $(5 \mathrm{~b}$ and $5 \mathrm{c}$ ) in place, meaning it actually appears as the circlip stamped out that part marked as Sect. 1. Moreover, it is noteworthy that this part failed at chamber pressure of about 4.5 MPa after having withstood several times a pressure level in the range of about $10 \mathrm{MPa}$. Thus, it seems very likely that the part failed due to thermal fatigue.

As a result, a threefold lesson should be kept in mind for the future: first, it is recommended to inspect the molybdenum parts exposed to thermal cycles with appropriate measures after a number predefined cycles, second, one might consider an improved thermal protection for that part, and third, one might consider the usage of a different material.

Apart from the rocket motor, open questions also concerned the protective shields before the execution of experiments. Four flat plates made of different materials were manufactured to protect the RPC most of the time from the hot exhaust plume. The different plates consisted of tungsten, molybdenum, graphite and aluminum oxide. However, only the tungsten plate was used since it proved to be suitable throughout all tests, and was correspondingly not exchanged. According to our visual inspections, the tungsten plate did not suffer from erosion, but exhibited a hairline crack by the end of the measurement campaign.

\section{2 (Raw) Data of measurements}

In the following, a first glance is provided on the (raw) data of the various measurement methods for the purpose of showing the applicability.

\subsubsection{Combustion chamber pressure}

Before the tests, one of the questions concerned the behavior of the nozzle. Will the nozzle throat open up due to abrasion or due to high heat loads, will the nozzle throat remain constant or will some kind of deposition take place? This question is addressed in the following.

The pressure evolution for the HTPB0514 propellant grain is provided in Fig. 10. Initially, a constant pressure evolution was targeted, which was the reason for choosing an end-burner type grain. The constant pressure for that propellant grain was predicted to be at $2.9 \mathrm{MPa}$ and $5.1 \mathrm{MPa}$. In fact, it can be seen that the pressure level directly after the ignition tends to converge to the predicted value. However, it can also be seen that with progressing time, the chamber pressure increases for all configurations. This is attributed to the deposition of alumina along the inner surface of the nozzle.

Evidence for that is provided in Fig. 11. The image shows a deposition layer that could be removed from the inside of the nozzle after the tests with HTPB0514. The outer contour of that deposition essentially corresponds to the inner contour of the truncated ideal contour (TIC) nozzle. Due to the predicted exhaust components and due to the whitish color, it appears safe to say that the deposition consists mainly of alumina. Next, it can be observed that the deposition process is only repeatable within some limits, which explains the difference regarding the pressure evolution for the same configurations.

In detail, the deposition process is understood as following: after ignition, molten alumina is deposited along the cold surface. Seconds into the operation of the motor, the deposition process is still ongoing, which is evidenced by the pressure increase due to the increase of the Klemmung. One reason might be that the motor is still not in thermal equilibrium. Further, it could also be associated with the temperature evolution in the nozzle. At the nozzle throat, the gas temperature is about $2800 \mathrm{~K}$ and above the melting 
temperature of alumina of $2345 \mathrm{~K}$. However, farther downstream it quickly decreases below that melting temperature to $\approx 2260 \mathrm{~K}(\mathrm{Ex} 2)$ or $\approx 1400 \mathrm{~K}(\mathrm{Ex} 3)$ at the nozzle exit (Table 1). In other words, the conditions along the contour of the nozzle promote the deposition of alumina. Finally, the pressure evolution suggests an upper limit for the deposition. After reaching that limit, chips from the deposition might break off, which is indicated by small spikes notable over the course of the overall trend, e.g. for configuration Ex1-P2 or Ex3-P2. Note that the deposition's growth and break-up process at the nozzle exit was also observed in the high-speed schlieren, in the particle image velocimetry (Fig. 14) and in the AEM (Fig. 19) recordings.

To conclude, the tail in the evolution of one of the two Ex2-P1- and Ex1-P1-cases shall be addressed. For that case, it is assumed that the burn surface is somewhat tilted, which could result in such a slowly decreasing pressure evolution since the burn surface would then advance in one of the bottom corners and provide less and less mass flux. A clogged pressure port or a malfunction of the pressure sensor can be excluded since the redundant pressure sensor signal (not depicted) shows the same evolution.

The pressure evolution of the HTPB $0514 \mathrm{Al}_{2} \mathrm{O}_{3}$ with the inert alumina filler depicted in Fig. 12 shows a behavior which is in contrast to the previous one. For that propellant type, a constant pressure level for the two smaller throat diameters of 3.0 MPa and 5.3 MPa was predicted, and as it can be seen, this is well matched. The finding regarding the rather constant pressure level is consistent with the overall observation after the experiments where no strong deposition was found.

The pressure evolution of the remaining HPTB1814 grain is presented in Fig. 13. The pressure evolution is in the order of the predicted range of $2.3 \mathrm{MPa}, 4.0 \mathrm{MPa}$, and 6.2 $\mathrm{MPa}$, and slowly decreasing. Deposition could be found after the tests, however to a lower degree in comparison to HTPB0514. The occasional spikes in the pressure evolutions are attributed to the break-up of coated alumina chips during a run. Overall, these previously described elements indicate that a similar deposition process takes place for the HPTB1814 propellant as for HPTB0514. At ignition, the alumina particles are cooled by the nozzle material (thermal inertia) and solidify on the wall. However, in contrast to the HPTB0514 propellant, it appears as the nozzle throat approaches over time its predicted value, which is calculated for the nozzle throat to be about $3130 \mathrm{~K}$. This is above the melting temperature of alumina leading to the observed pressure drop over time. The remaining layer of alumina after the test evidences that the tests are not long enough or the set-up allows the nozzle material to keep a low temperature. Generally, the chamber pressure is at a lower level, which is easily explained by the lower burn rate (Table 5) for that propellant, while using the same nozzle configurations for all propellants.

An impression regarding the thickness of the deposited material after the runs can be gained from Table 2. It provides an averaged throat diameter before and after the run ('initial diam.' vs. 'end diam.') and the layer thickness after the run. However, please keep in mind that the values are difficult to take since the throat opening is not necessarily round, but rather fringy depending on the alumina deposition process.

\subsubsection{Particle image velocimetry (PIV)}

A classical 2D-2C particle image velocimetry setup was applied for the purpose of determining the velocity distribution of the jet downstream from the nozzle exit. In more detail, the interconnecting equipment is based on a system by LaVision to which the main components, such as the Ultra CFR Nd:YAG laser by Quantel/Big Sky Laser and two pco.edge 5.5 cameras by PCO, are connected.

Applying PIV measurements on a solid propellant exhaust jets is not a novelty (see [21]). However, it is quite unusual since it poses a very challenging environment due to the background irradiation due to the hot particles, the high velocities and the high temperature. Atypical is the usage of a bandwidth filter in the $532 \mathrm{~nm}$ range in front of the cameras to filter out the disturbing background irradiation.

Figure 14 shows raw, inverted intensity images as acquired during these measurements. The results all stem from the same nozzle configuration, which is Ex3-P2, while they differ with respect to the propellant type. The intention is to asses these images qualitatively with respect to their feasibility for PIV evaluation. Good PIV images show distinct particle images (here in black) and/or distinct patterns that can be cross-correlated with the second PIV image (which is not shown here).

It can be seen that the raw images for the tests with HTPB 0514 and $\mathrm{HTPB} 0014 \mathrm{Al}_{2} \mathrm{O}_{3}$ feature clear patterns in the shear layer, and distinct particle images can be detected in the core flow and shear layer. Both, patterns and particles, can be used for cross-correlation evaluation. This is especially true for the case with $\mathrm{HTPB} 0014 \mathrm{Al}_{2} \mathrm{O}_{3}$. Here, it appears as the (supposedly) inert particles are relatively large and remain in the core flow, while finer particles can be accelerated laterally into the shear layer. For both configurations, a PIV evaluation is promising. This is not necessarily the case for the HTPB1814 for which the image appears to be relatively blurry without distinct particles. This can be explained, on the one hand, with the higher particle concentration, which is making the jet optically opaque, and on the other hand, with the stronger background irradiation of the particle. Thus, no velocity fields can be expected for the tests with HTPB1814. 


\subsubsection{Direct image particle size determination (DIPSD)}

The setup used for DIPSD relies on the same laser and interconnecting equipment as for the PIV setup. However, to provide a better spatial resolution the PCO1600 camera by PCO was equipped with the Model K2 DistaMax lens system by Infinity Photo Optical. As a result, the field of view for this setup was $3.4 \mathrm{~mm} \times 4.0 \mathrm{~mm}$.

An exemplary image is provided in Fig. 15. The original idea was to capture glare points for the particle size determination. However, this exemplary image does not exhibit glare points, thus further investigations must show if this is actually possible with this setup. Nevertheless, it might also be used to gain spatially highly resolved velocimetry data just by applying a standard PIV evaluation on the raw data set. Apart from PIV and L2F, this would be the third measurement technique providing insights into the velocity distribution of the rocket exhaust plume, and as such, also useful for cross-checks.

\subsubsection{Laser-2-focus (L2F)}

In short, the laser-2-focus measurement method is based on a time-of-flight measurement of a particle captured between the focuses of two laser beams [22-28]. The velocity is determined by means of the distance between the two foci and the corresponding time-of-flight. Exemplary results of which for a location downstream of the hot exhaust jet for the three propellant types are given in Fig. 16. The graph shows the velocity of the particles as function of the corresponding counts. In total, 2000 (randomly selected) samples are evaluated here. The velocity itself must still be assessed in context with the flow topology. Of interest now is only the feasibility of the measurements, and it can be seen that data can be extracted from tests with all three propellant types. Taking into account that no PIV evaluation appears to be possible for the HTPB1814 propellant, this finding is unexpected due to the high optical density of the exhaust plume. The L2F measurement, in that case, still captures a significant amount of events, ergo valid data, for this optically rather dense flow, and thus unexpectedly provides additional information of the jet.

\subsubsection{Spectroscopic measurements: FTIR, UV-Vis and AEM}

UV-Vis emission spectroscopy was performed using an OceanOptics USB2000 spectrometer covering a spectral range from 200 to $850 \mathrm{~nm}$ (relative intensity calibration valid from $500 \mathrm{~nm}$ upwards) in a cylindrical volume $30 \mathrm{~mm}$ downstream from the nozzle exit and of about $7 \mathrm{~mm}$ diameter. Figure 17 depicts a typical UV-Vis emission spectrum, showing the plume emission of Run012-V29-End at $1.95 \mathrm{~s}$. The particle phase grey body radiation as well as the atomic emission lines of $\mathrm{Na}$ and $\mathrm{K}$ are visible. Also the inferring emission lines of both L2F and the PIV laser system can be seen. The particle phase emission will be evaluated to get the history of particle emission intensity and of particle grey body temperature.

Fourier transform IR (FTIR) emission spectroscopy was performed using an ABB MR 304 covering a spectral range from 1 to $8 \mu \mathrm{m}$ in a cylindrical volume $30 \mathrm{~mm}$ downstream from the nozzle exit and of about $25 \mathrm{~mm}$ diameter. Figure 18 depicts a typical IR emission spectrum, showing the molecular emission lines of $\mathrm{CO} 2, \mathrm{CO}, \mathrm{H} 2 \mathrm{O}$ and $\mathrm{HCl}$ during Run031-V06-End. The emission lines of $\mathrm{HCl}$ will be used to determine the gas temperature. The particle radiation in the IR can be observed in all FTIR spectra as a continuous background and depends on the aluminum amount of the propellant. The spectrum depicted in Fig. 18 is taken for a low aluminum content case, where the particle background is barely visible compared to the gas phase emission.

Alumina emission measurement (AEM) is effectively a position resolving two-color pyrometer. It is an in house development, build from two cameras taking pictures at $630 \mathrm{~nm}$ and $700 \mathrm{~nm}$, respectively. A dichroic mirror at $650 \mathrm{~nm}$ splits the image into two separate paths, which then are filtered by bandpass filters of $10 \mathrm{~nm}$ FWHM. A detailed publication will follow. In the vicinity of these two wavelengths, only grey body radiation is emitted. From the intensity ratio of two synchronized images particle (Fig. 19) the temperature and particle density distribution of the plume will be derived. In Fig. 19 at the top, the protective shield for the RPC is visible. At the nozzle exit, the externally growing alumina depositions along the boundary of the jet can be observed, which were also observed in the PIV imaging (Fig. 14)

\subsubsection{High-speed schlieren (HSS)}

Figures 20 and 21 show an instantaneous and an averaged high-speeds schlieren image, respectively. For the acquisition, a Z-type schlieren setup readily installed in VMK was used and the images were recorded with a Photron Fastcam SA-X2 type 1080K-M4. The main focus of the HSS recordings regards the monitoring of the experiments, on the one hand, and on the other hand, the extraction of the flow topology of the plume. In fact, features of the flow topology can be observed in Fig. 21.

The image features a shock evolving from the right side of the nozzle which is then reflected at the shear layer. This feature is more distinct on the left side which is attributed to the orientation of the knife edge. The vertically aligned knife edge introduced a gradient in the lateral direction. On top of that, the highly turbulent wake flow notable in Fig. 20 has an impact on the signal-to-noise ratio of the mean flow features, which also impede the isolation of mean flow features. 
Next, the propellant used for this test contains 5\% aluminum, which additionally decreases the transmissivity inside the plume. Nevertheless, the presence of such a shock system is notable.

Further, the highly turbulent flow of various scales indicate a strong heating of the fluid of the base region. This is in contrast to tests with a cold exhaust jet (not shown here) where the flow in the base region is typically less turbulent. In other words, in comparison to cold jet tests, different conditions are imposed in the base region due to the presence of a hot jet.

\subsubsection{Aerodynamic particle sizer (APS)}

Apart from the RPC, a second system has been integrated in the wind tunnel to capture the particle size distribution. Namely, it is the Aerodynamic Particle Sizer APS 3321 by TSI in combination with the diluter 3302A [29]. The particles are extracted from the nozzle exhaust plume far downstream (about $3 \mathrm{~m}$ ) from the jet.

The APS is equipped with two methods to assess the particle size. One method is based on the aerodynamic acceleration through a nozzle, and a second method, which is based on the scattering of laser light. Further details to the measurement principles including a schematic of the device are available in Refs. [30, 31]. In combination, the results can be correlated and invalid particle clusters can be removed. Invalid particle or particle clusters would appear as outliers when the scattering intensity is related to the particle size. As Fig. 22 shows, this is not the case for the current measurements captured with the APS. The graph depicts the Stokes corrected aerodynamic particle size distribution for alumina $\left(\rho_{\mathrm{Al}_{2} \mathrm{O}_{3}}=3.95 \mathrm{~g} / \mathrm{cm}^{3}\right)$. At that instant in time, it appears as most of the particles can be found in the sub-micrometer range at about $0.7 \mu \mathrm{m}$.

A comparison between the particle size distributions collected in the exhaust plume of the various propellants comes to the same conclusion. The results in Fig. 23 indicate that most particles are found in the sub-micron range independently from the type of the propellant. However, these results only show part of the truth and require further scrutiny such as comparisons with other measurement techniques, e.g with the RPC [20]. First, the APS only measures particles up to an aerodynamic diameter of $20 \mu \mathrm{m}$. Second, the loss of particles, meaning the penetration efficiency, in the supply tube for the APS must be considered. For instance, it is estimated that only $29.3 \%$ of the particles featuring a diameter of $10 \mu \mathrm{m}$ pass, while particles $>13 \mu \mathrm{m}$ are completely filtered out. Third, the raw particle image for PIV shown in Fig. 14 clearly indicates a difference between the propellants with aluminum and alumina. The particles for HTPB0014Al2O3 appear larger, which is consistent with the initial alumina distribution (Sect. 2.2). In short, the measurement by the APS relies on a correct penetration efficiency correction and is suitable only for the measurement of the small particles sizes. Nevertheless, these are actually the particles of interest since they are most relevant with respect to their impact on the atmosphere.

\subsubsection{Gardon gauge}

The radiative heat flux from the exhaust plume to its surrounding components is of special interest especially for the base region. For one of the rare experiments without protective shield, Fig. 24 provides that quantity (low-pass filtered) in context of combustion chamber pressure for an experiment with 5\% aluminum propellant. The strong correlation to the start-up of the motor, indicated by the pressure increase, provides a strong foundation for the validity of the radiative heat flux data. After about $\Delta t=5 \mathrm{~s}$, a strong increase can be found, which is believed to correlate with the radiative flashes noted in the high-speed schlieren measurements towards the end of the experiments. It might be the result of chipped alumina depositions or of additional components being released and burned in the combustion chamber towards the end of a run. Further open questions such as the offset after the motor's shut-down run will be assessed in future analysis. For now, the approach has shown that measurements can be taken in such a manner.

\subsubsection{IR-thermography (IR)}

The IR recording in Fig. 25 shows why the PEEK plate (Fig. 8) did not withstand the heat flux in the base region. For orientation, only a section of the base plate is shown and the edge of the main cylinder (edge partially visible) is on the left side while the nozzle is on right side. The dots on the base plate represent markers which will be used later for scaling and image distortion. Further, the images were recorded with the ImageIR 8300 camera by InfratTec.

It can be seen that the black-colored aluminum plate reaches an average temperature above $400 \mathrm{~K}$ for this instant in time while the hotter spots can obviously be found at the section surrounding the nozzle. Keep in mind that transient flow conditions, like start-up or shut-down, might impose even higher heat loads since the hot gases coming from the nozzle are then more prone to be sucked into the recirculation region. 


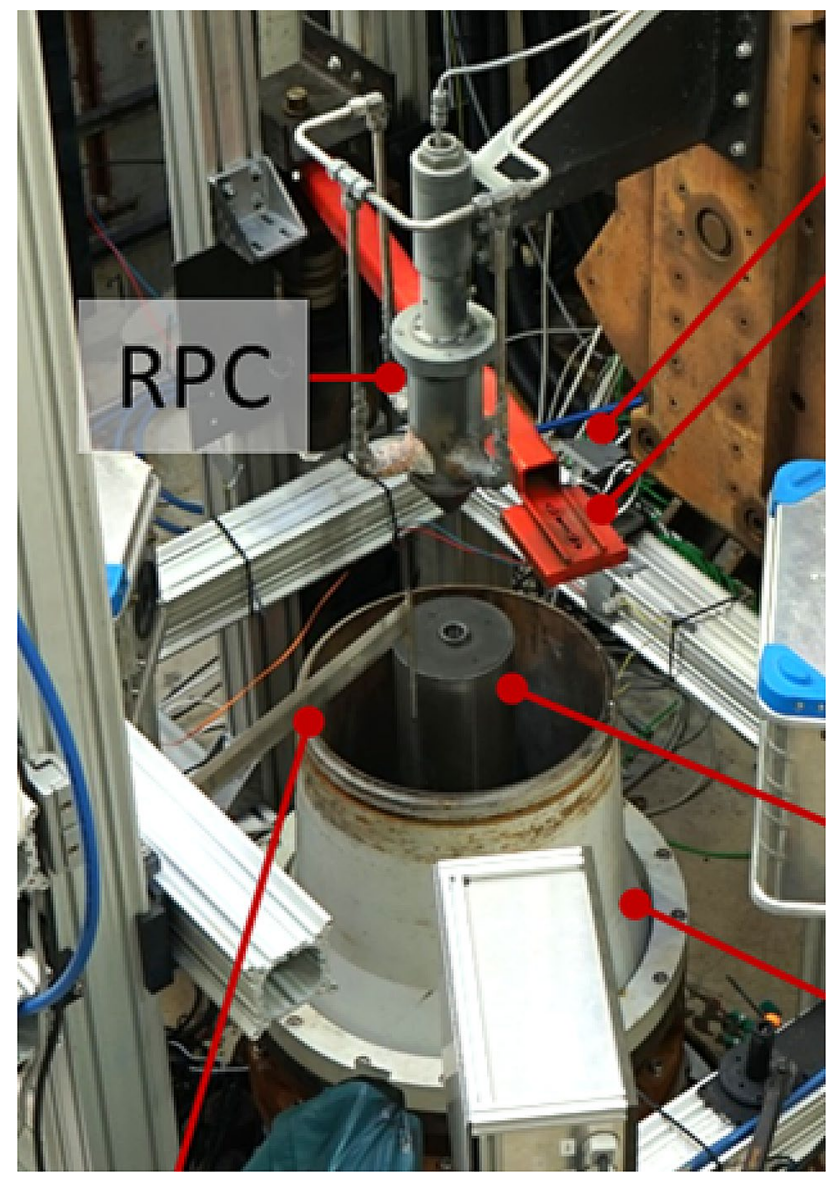

Fig. 5 Close-up of the wind tunnel model extracted from Fig. 4

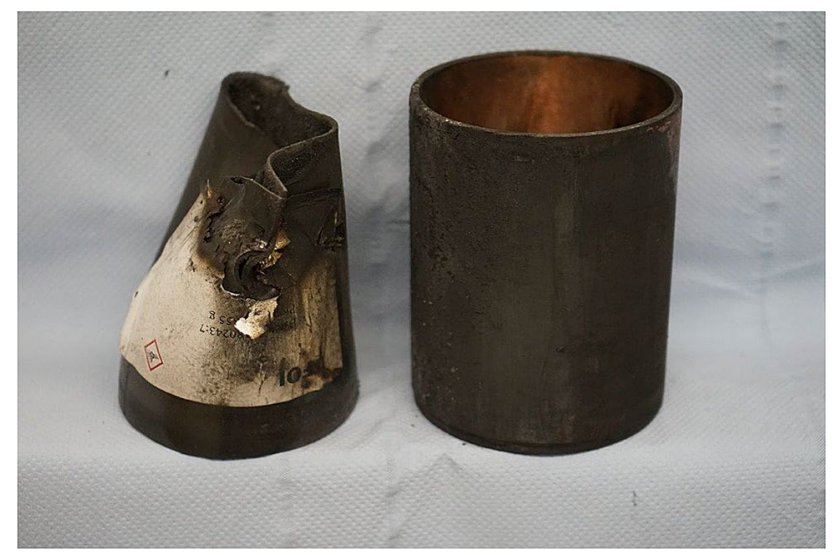

Fig. 6 Thermal insulation of the walls with carbon black insulation coat (left) and a phenolic liner (right) after usage

\subsubsection{Rocket plume collector (RPC)}

The 'rocket plume collector' has been developed in the frame of ESA-EMAP project. The probe is depicted in Fig. 5 and its schematic is shown in Fig. 26. In short, particles are

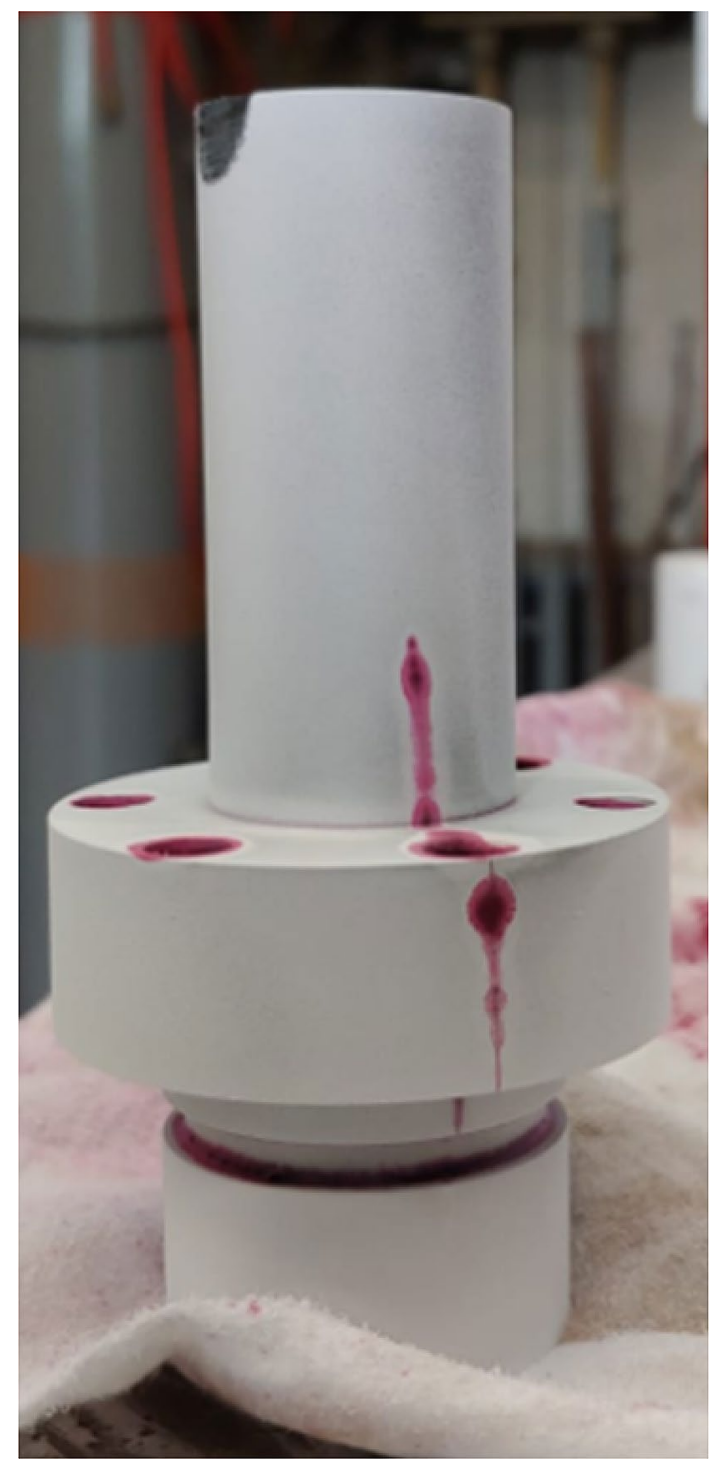

Fig. 7 Penetrant dye inspection of the tungsten nozzle

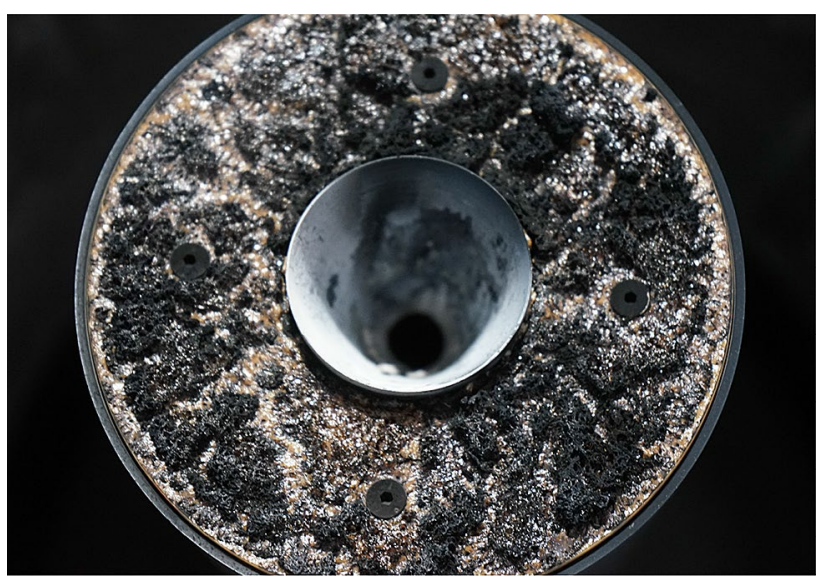

Fig. 8 (Burned) PEEK base plate after a hot firing test 


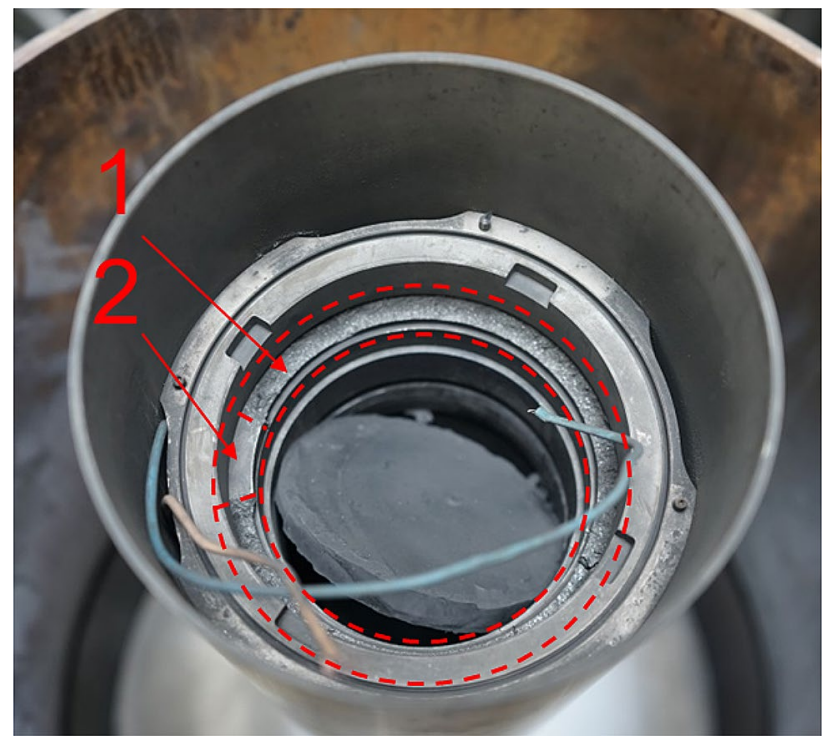

Fig. 9 Top view into the rocket motor after the nozzle block failure. Section 1 marks the stamped out section and Sect. 2 marks the remaining original section

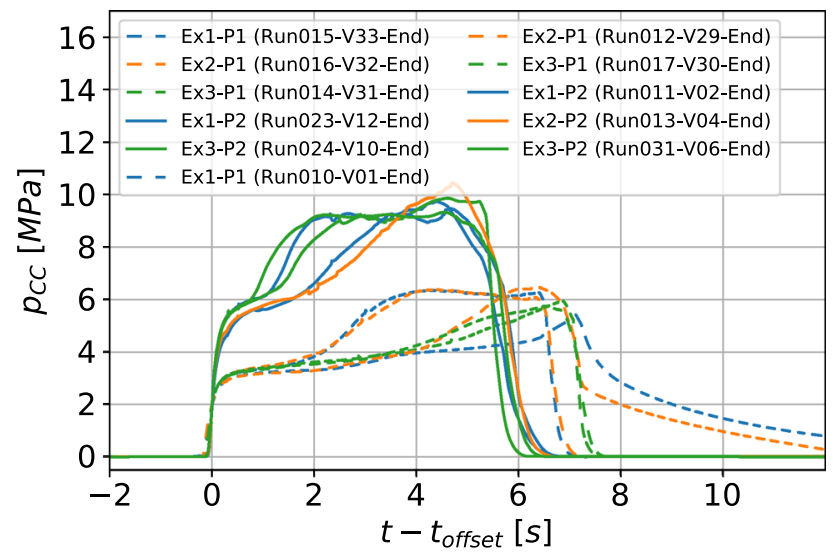

Fig. 10 Combustion chamber pressure evolution for the propellant with 5\% aluminum (HTPB0514)

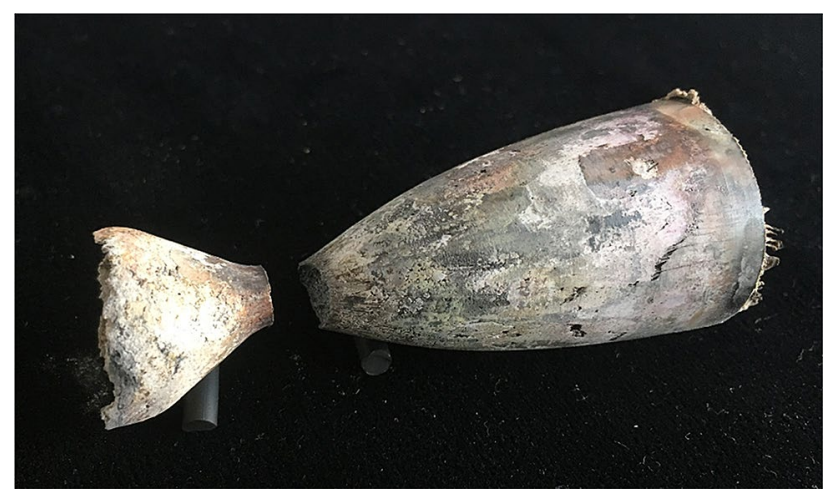

Fig. 11 Deposition of alumina in the nozzle for the propellant $5 \%$ aluminum propellants HTPB0514 (after removal from the nozzle contour)

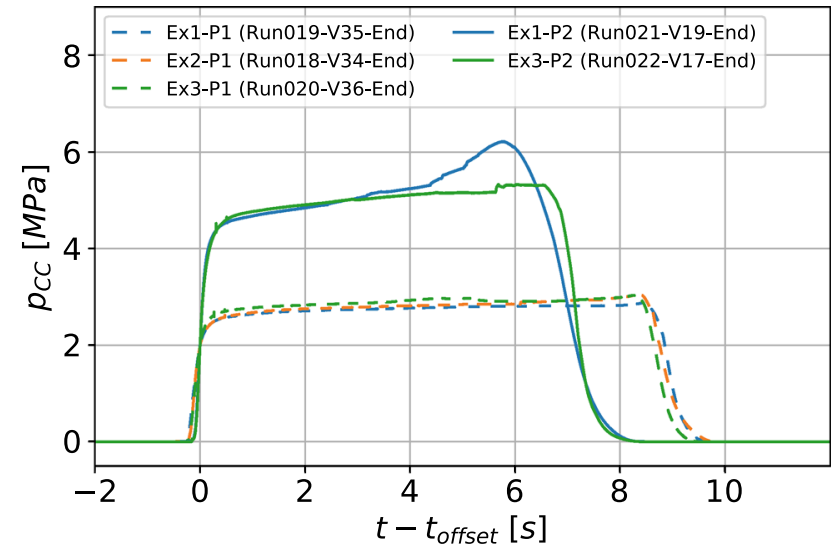

Fig. 12 Combustion chamber pressure evolution for the propellant with 5\% alumina (HTPB0514Al2O3)

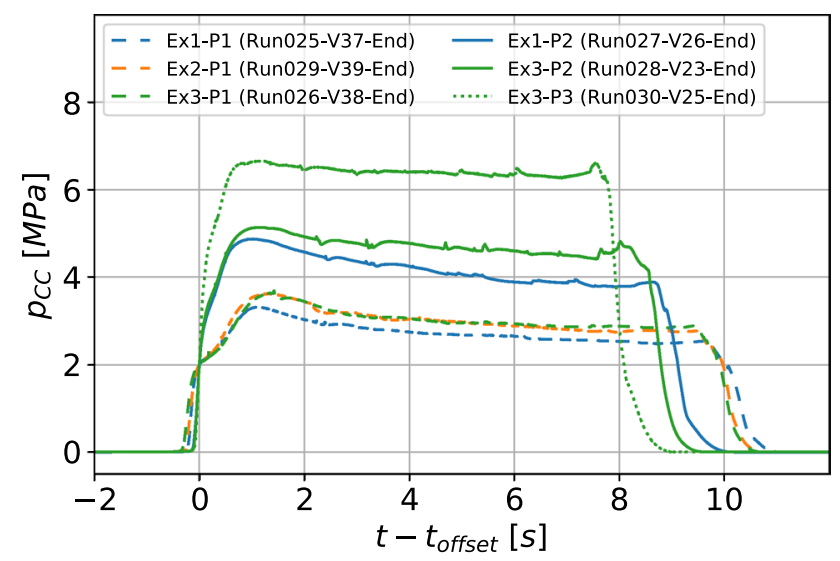

Fig. 13 Combustion chamber pressure evolution for the propellant with $18 \%$ aluminum (HTPB 1814)

sampled through an opening at the tip of the RPC, which are then internally slowed down and quenched with a quenching liquid. Its objective is to deduce the particle size in a post-processing step. The first preliminary results can be accessed in Maggi et al. [20]. Further insights to the working mechanism and details to operational range can be extracted from Refs. [32-36].

\section{Lessons learned}

Lessons learned regarding the rocket motor:

- The glow plug as ignition device worked reliably.

- Carbon black has proven be a suitable thermal insulator. 


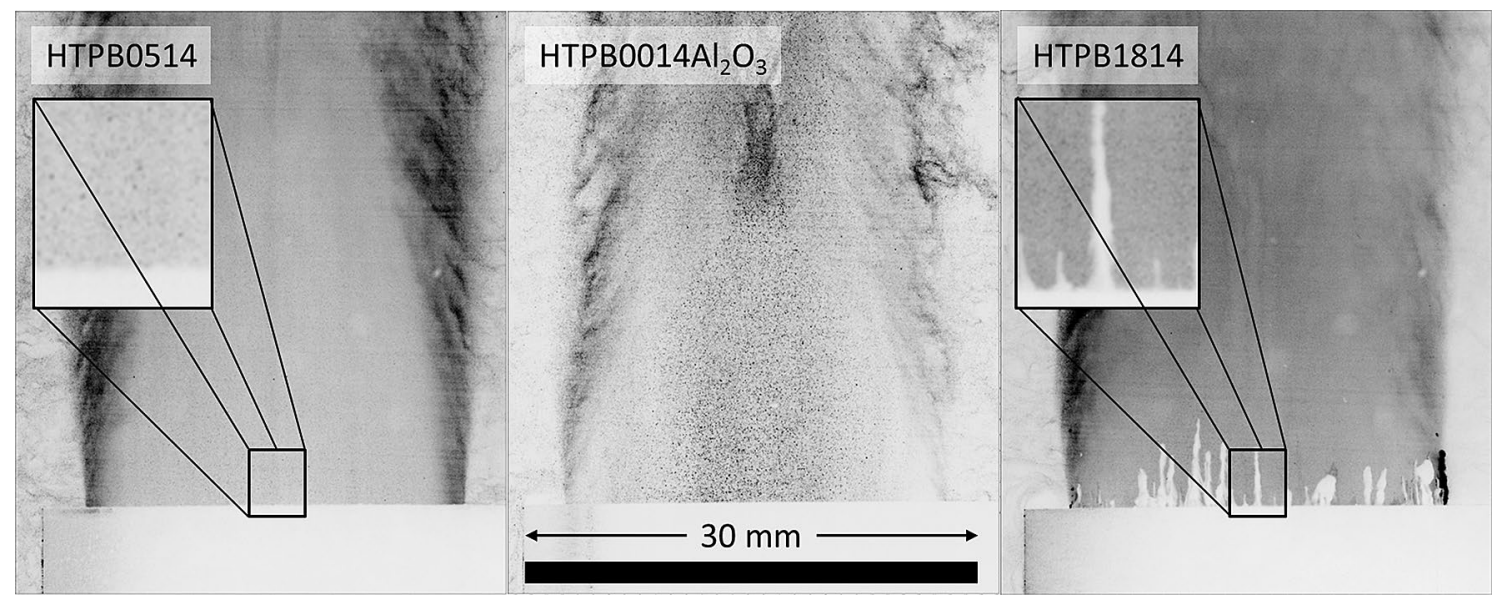

Fig. 14 Randomly selected (inverted) raw intensity images of the PIV measurements for tests with the Ex3-P2 nozzle and with the HTPB0514 (left, Run031-V06-End), HTPB0014A1_2O_3 (mid, Run022-V17-End), and HTPB1814 (right, Run028-V23-End) propel-

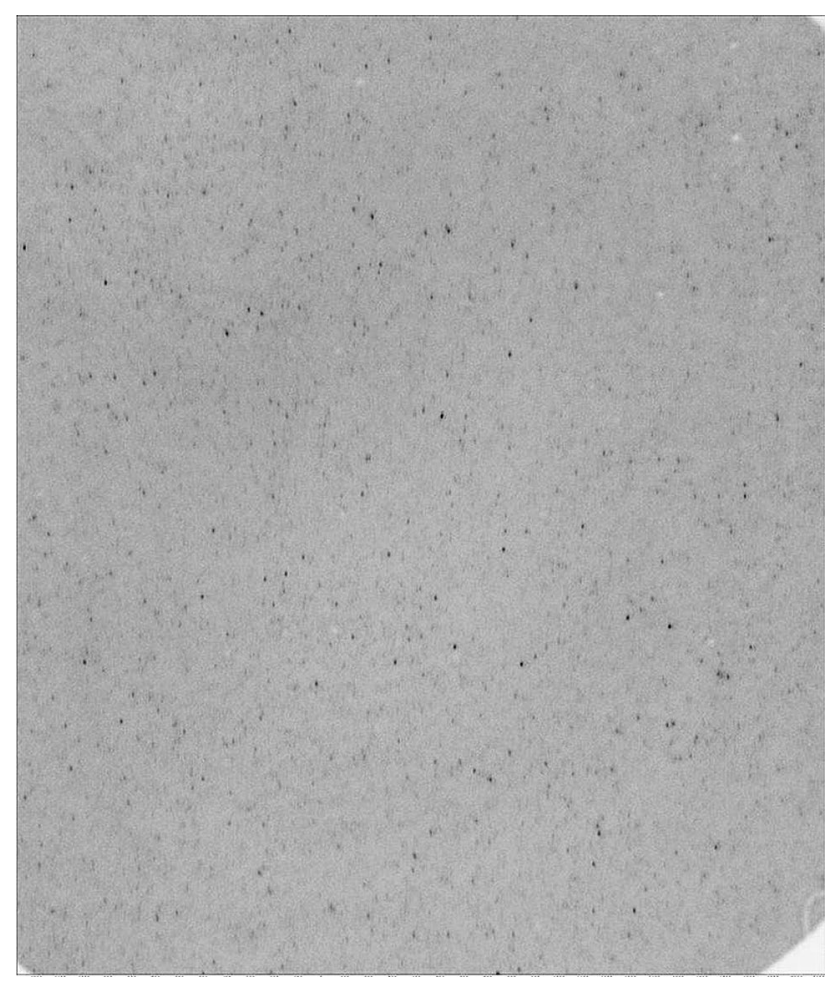

Fig. 15 Randomly selected (inverted) raw intensity images of the DIPSD measurements with the Ex3-P2 nozzle and with the HTPB0514 propellant grain (Run031-V06-End). The image/field of view corresponds to $3.4 \mathrm{~mm} \times 4.0 \mathrm{~mm}$ lant grain. Note that the streaks visible for the HTPB1814-case are the result of externally growing alumina depositions along the boundary of the jet

- Phenolic liners have already been used as thermal insulator in the past and will be used for comparable applications in the future again.

- A different approach must be followed for the failed molybdenum part. The options are as following: (1) Acquiring a better understanding of the material characteristics to cyclical heat and pressure loads, (2) implement regular, non-destructive metallurgic inspections, (3) integrate a thermal protection system at that section, and/ or (4) reconsider the material choice.

- Tungsten might have to be reconsidered as material for the nozzles since microcracks were detected already after a single run. Nevertheless, the corresponding nozzles have shown to withstand several further tests with no signs of leakage and without any constraints. However, it is difficult to justify such an outcome as baseline for future tests.

- When using propellants with 5\% aluminum, the nozzle throat diameter decreases over one run due to clogging causing a corresponding increase of the chamber pressure. Thus, the aluminum content should be increased to increase the temperature in the nozzle throat, which in turn will very likely reduce the solidification of alumina along the surface of the nozzle.

- The protective shield made of tungsten was able to withstand the heat and pressure loads for more than 20 runs. 
Fig. 16 L2F velocity measurement of the particles in the supersonic exhaust jet

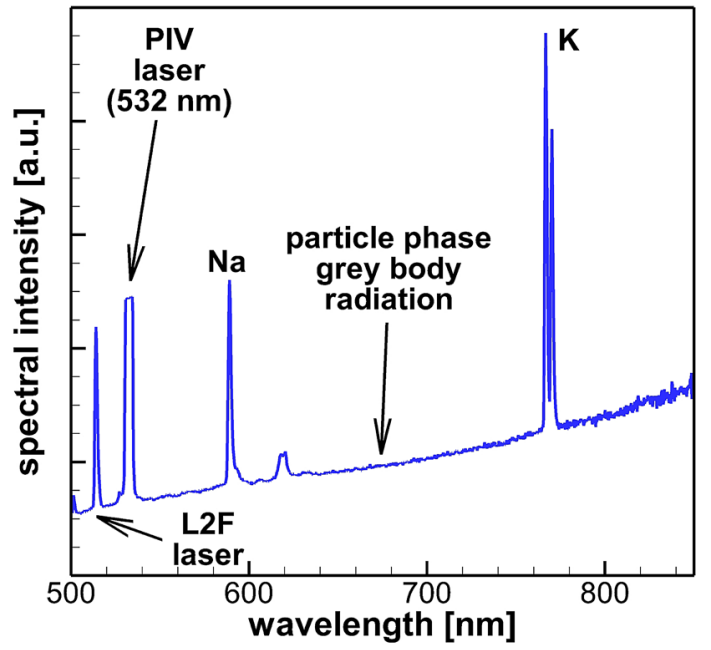

Fig. 17 UV-Vis emission spectrum of the rocket exhaust plume (5\% aluminum, Run012-V29-End)

Lessons learned regarding the applied measurement techniques:

- Velocimetry measurements methods such as PIV, L2F and the off-use DIPSD appear to be suitable to derive velocity data in a solid exhaust plume. For an optically relatively dense plume ( $18 \%$ aluminum content), only L2F managed to capture valid data.

- Spectroscopic measurement methods reliably provided intensities as function of the wavelength. These results are promising to derive the temperature distribution of gas and particles.
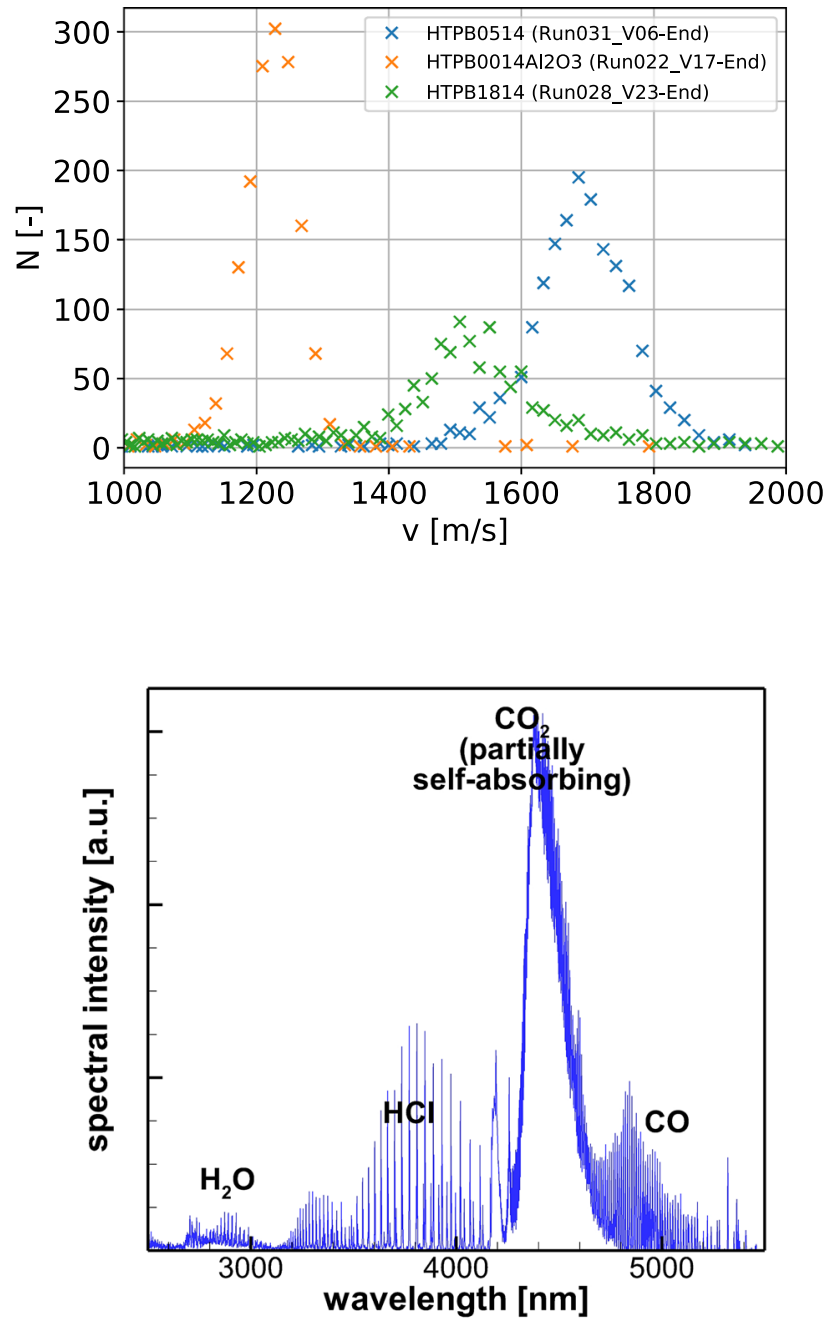

Fig. 18 Fourier transform IR (FTIR) emission spectroscopy of the rocket exhaust plume (Run031-V06-End)

- Well-established measurement methods such as HSS, IR and pressure measurements have fulfilled their expectations. Thus, data regarding flow topology, the temperature of the base plate, and the chamber pressure evolution is accessible.

- The Gardon gauge acquired data attributable to the radiative heat flux of the plume.

- Particles were successfully extracted from the hot exhaust plume by means RPC probe [20].

- Further downstream from the nozzle exhaust, the APS reliably gathered data, which can be used for crosschecks with the RPC. 
Fig. 19 Raw images at $630 \mathrm{~nm}$ and $700 \mathrm{~nm}$ taken by the AEM for a test with $18 \%$ aluminum (Run028-23-End)

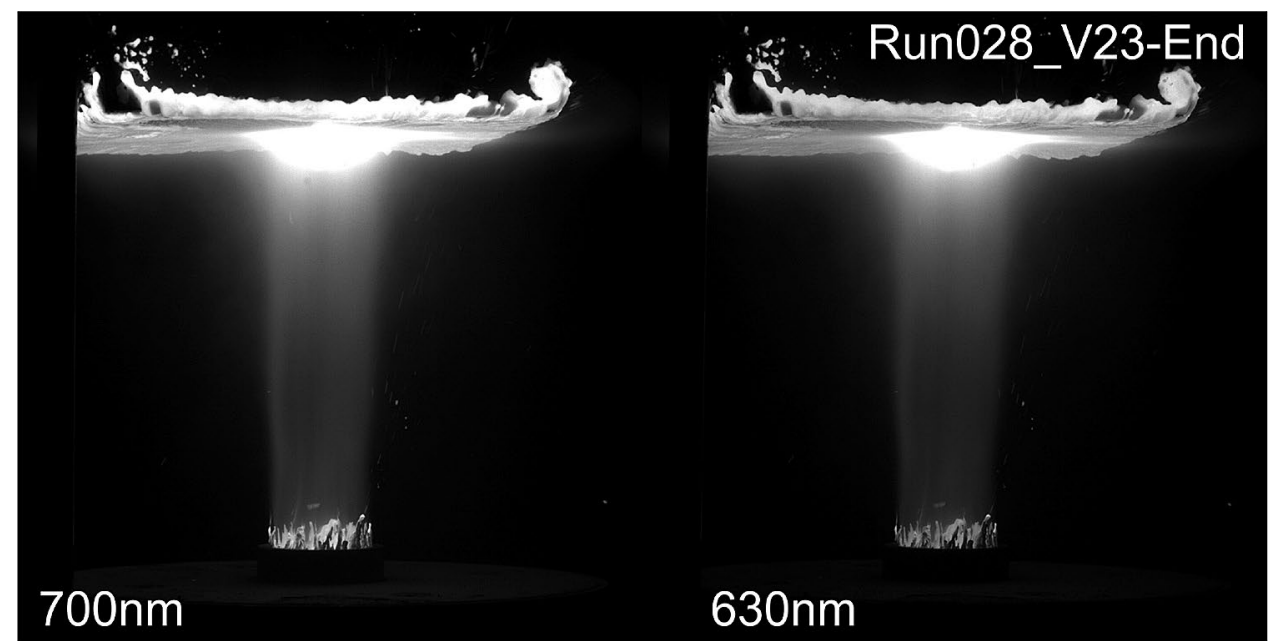

\section{Conclusions and outlook}

The current study presents the activities in the frame of ESA-EMAP for the characterization of a rocket exhaust plume. In the frame of this report, aspects to the functionality of rocket motor itself and the applicability of the various measurement techniques were discussed. Despite the fact that some components, such as the molybdenum nozzle block, require improvements the rocket motor has proven its overall functionality. Further, on a first glance, the measurement results are very promising. Thus, as next steps, the

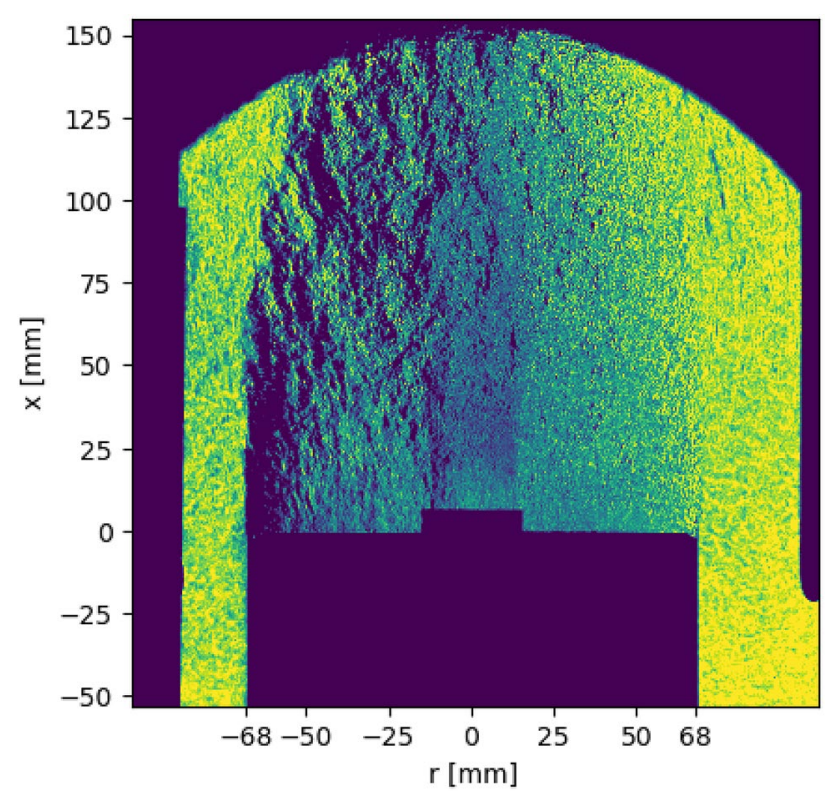

Fig. 20 False color representation of an instantaneous high-speed schlieren image for a test with 5\% aluminum (Run031-V06-End) individual measurements will be analyzed in depth and in context with each other to extract more details regarding the particles in a rocket exhaust plume.

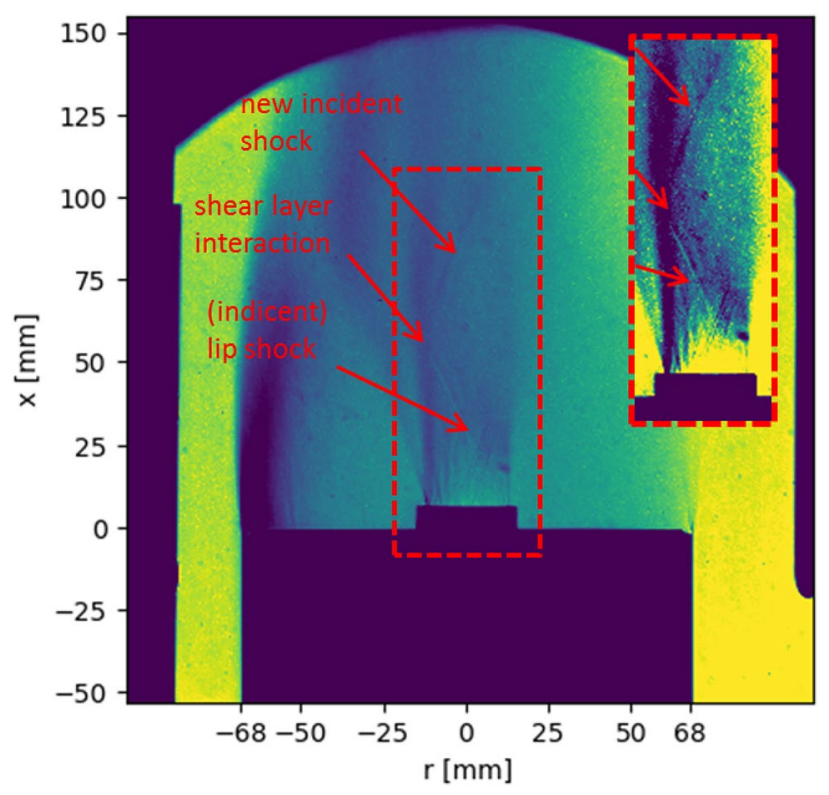

Fig. 21 False color representation of an averaged high-speed schlieren image for a test with 5\% aluminum (Run031-V06-End) 


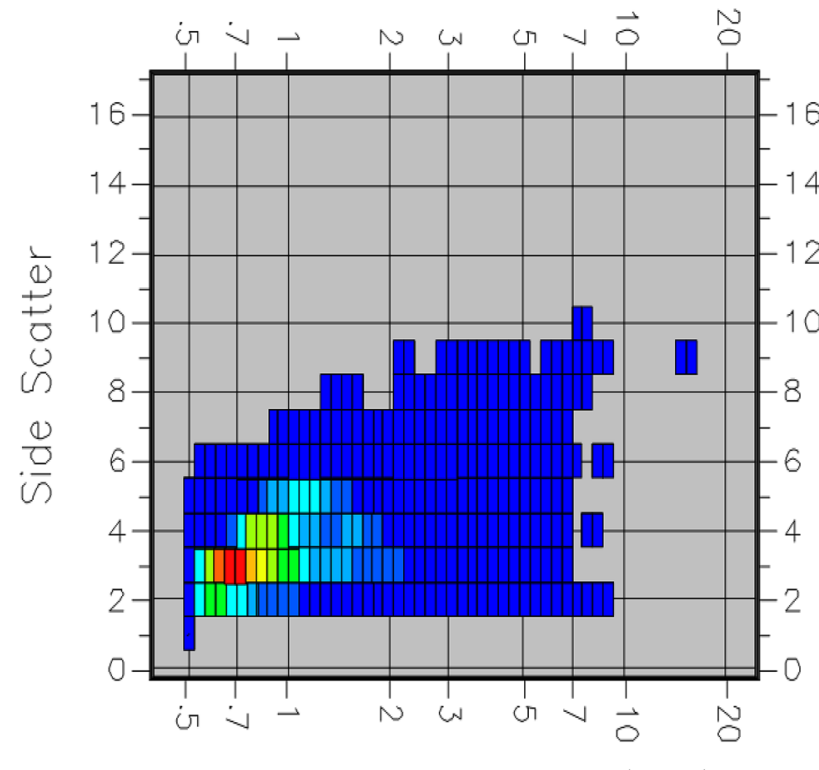

Aerodynamic Diam. (um)

Fig. 22 Correlation plot between aerodynamic particle size and laser light scattering measured with the APS at a randomly picked point in time for a test with 5\% aluminum (Run031-V06-End)

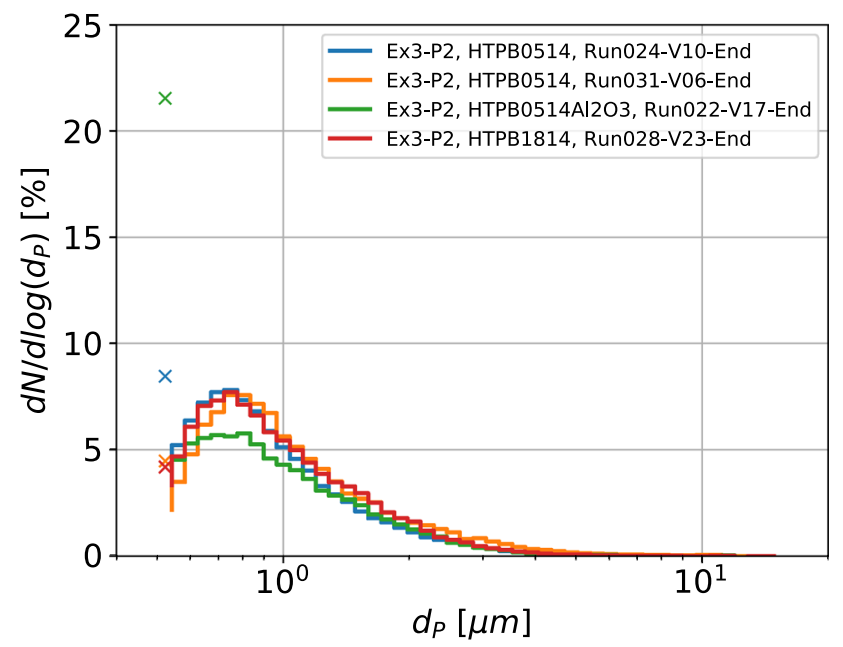

Fig. 23 Percentaged particle size distribution (penetration efficiency corrected) for the Ex3-P2 configurations
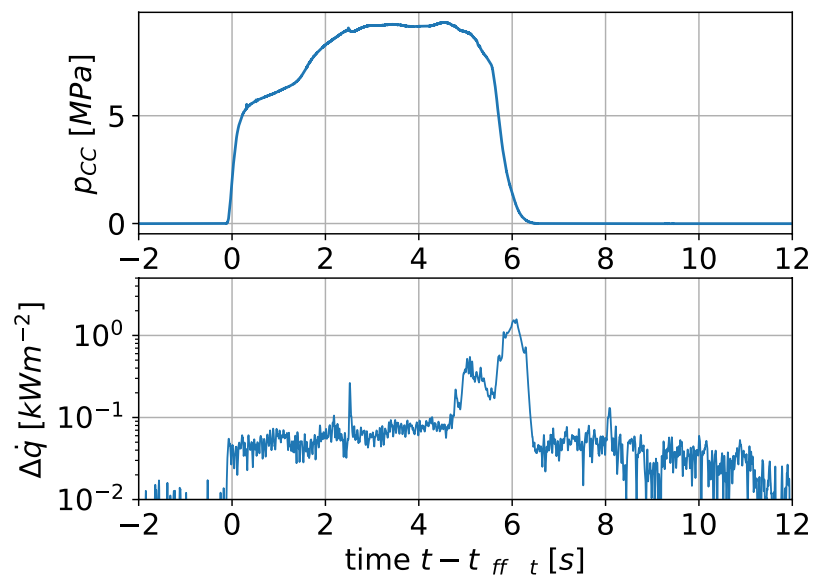

Fig. 24 Combustion chamber pressure in comparison with the (lowpass filtered) radiative heat flux from the exhaust plume of a 5\% aluminum-content propellant measured by a Gardon gauge (Run031V06-End)

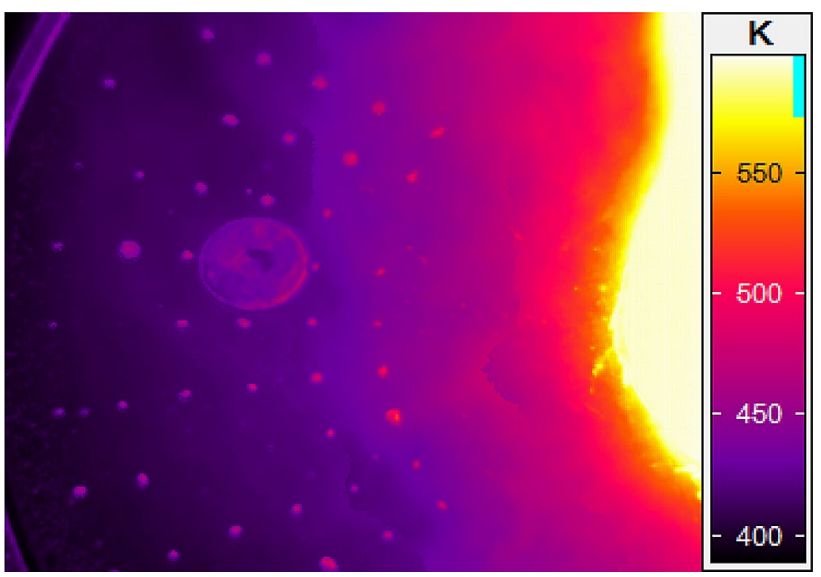

Fig. 25 IR recording of the base plate for a test with 5\% aluminum (Run031-V06-End) at a randomly picked point in time 


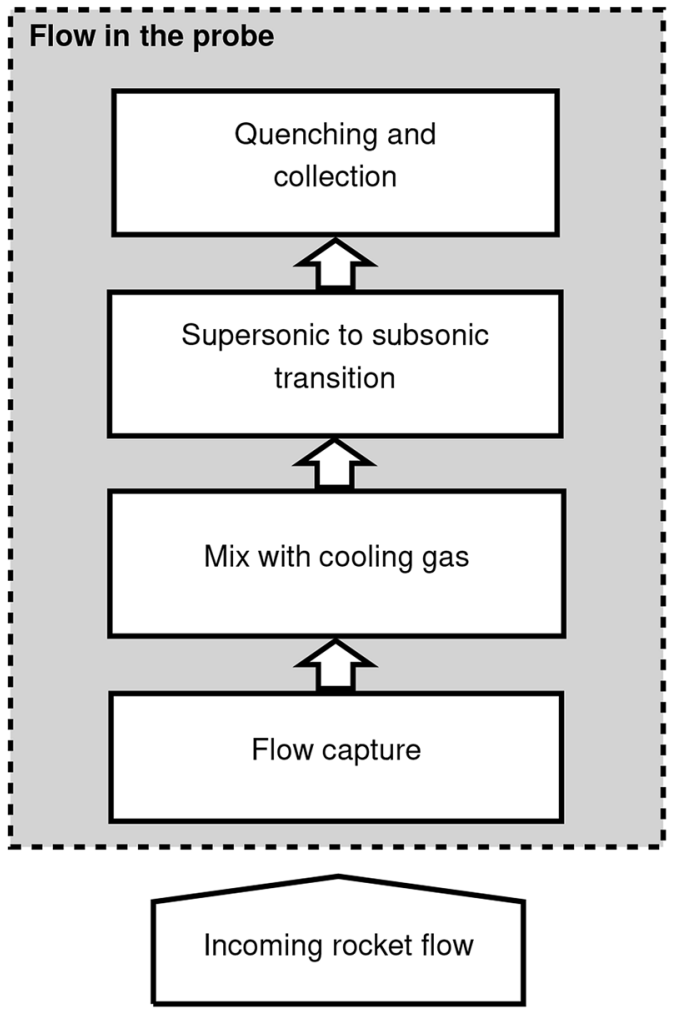

Fig. 26 Schematic of the rocket plume collector RPC

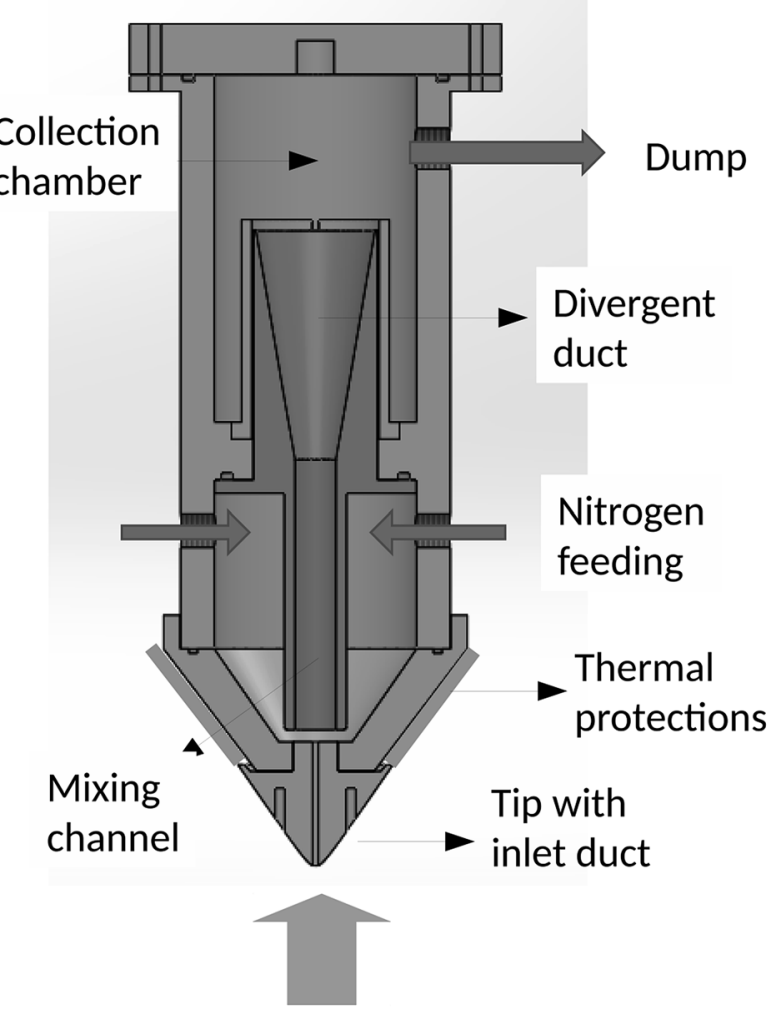

\begin{abstract}
Acknowledgements Financial support has been provided by the European Space Agency (ESA) in the framework of the project 'Experimental Modelling of Alumina Particulate in Solid Boosters' (ESA-EMAP). Thanks to all members of team and colleagues coming from the Space Propulsion Lab (SPLab) of the Politecnico di Milano, the Department of Energetic Materials of the Swedish Defence Research Agency (FOI), the DLR department Engine Measurement Systems (AT-OTM) and the DLR department of Supersonic and Hypersonic and Hypersonic Technologies Department (AS-HYP). Further, thanks a lot to the colleagues and the VMK Cologne staff for their support!
\end{abstract}

Funding Open Access funding enabled and organized by Projekt DEAL.

Open Access This article is licensed under a Creative Commons Attribution 4.0 International License, which permits use, sharing, adaptation, distribution and reproduction in any medium or format, as long as you give appropriate credit to the original author(s) and the source, provide a link to the Creative Commons licence, and indicate if changes were made. The images or other third party material in this article are included in the article's Creative Commons licence, unless indicated otherwise in a credit line to the material. If material is not included in the article's Creative Commons licence and your intended use is not permitted by statutory regulation or exceeds the permitted use, you will need to obtain permission directly from the copyright holder. To view a copy of this licence, visit http://creativecommons.org/licenses/by/4.0/.

\section{References}

1. Schmid, O., Reeves, J., Wilson, J., Wiedinmyer, C., Brock, C., Toohey, D., Avallone, L., Gates, A., Ross, M.: Size-resolved particle emission indices in the stratospheric plume of an Athena II rocket. J. Geophys. Res. Atmos. 108(D8) (2003). https ://doi.org/10.1029/2002JD002486

2. Jackman, C., Considine, D., Fleming, E.: In situ measurement of the aerosol size distribution in stratospheric solid rocket motor exhaust plumes. Geophys. Res. Lett. 25, 907-910 (1998)

3. Ross, M.N., Whitefield, P.D., Hagen, D.E., Hopkins, A.R.: In situ measurement of the aerosol size distribution in stratospheric solid rocket motor exhaust plumes. Geophys. Res. Lett. 26(7), 819-822 (1999)

4. Simmons, F.: Rocket exhaust plume phenomenology. Aerospace Press, El Segundo (2000)

5. Goethert, B.: Base heating problems of missiles and space vehicles. ARS paper, pp. 1666-61 (1961)

6. Kinefuchi, K., Okita, K., Funaki, I., Abe, T.: Prediction of inflight radio frequency attenuation by a rocket plume by applying CFD/FDTD coupling. In: 49th AIAA/ASME/SAE/ASEE joint propulsion conference, San Jose, CA, AIAA 2013-3790, 14-17 July 2013

7. Triesch, K., Krohn, EO.: Die Vertikale Meßstrecke der DFVLR in Köln-Porz (Stand 1986), DFVLR-Mitt. 86-22. Wissenschaftliches Berichtswesen der DFVLR, ISSN 0176-7739, Postfach 906058, 5000 Köln 90 (1986)

8. DLR ACG Vertical Test Section Cologne (VMK), Supersonic and Hypersonic Technology Department. http://www.dlr.de/ 
as/en/desktopdefault.aspx/tabid-194/407_read-5445/ (2019). Accessed 14 Mar 2019

9. Saile, D., Kirchheck, D., Gülhan, A., Banuti, D.: Design of a hot plume interaction facility at DLR Cologne. In: Proceedings of the 8th European symposium on aerothermodynamics for space vehicles, Lisbon, Portugal, 2-6 Mar 2015

10. Ponomarenko, A.: RPA-tool for rocket propulsion analysis. In: Space propulsion conference (2014)

11. Anderson, J.D.: Modern compressible flow: with historical perspective, vol. 12. McGraw-Hill, New York (1990)

12. Saile, D., Kühl, V., Gülhan, A.: On the subsonic near-wake of a space launcher configuration without jet. Exp. Fluids 60(4), 50 (2019a). https://doi.org/10.1007/s00348-019-2690-9

13. Saile, D., Kühl, V., Gülhan, A.: On the subsonic near-wake of a space launcher configuration with exhaust jet. Exp. Fluids 60(11), 165 (2019b). https://doi.org/10.1007/s00348-019-2801-7

14. Saile, D., Kül V, Gülhan, A.: On subsonic near-wake flows of various base geometries. In: 13th International symposium on particle image velocimetry (ISPIV 2019), 22-24 July (2019c)

15. Saile, D.: Experimental analysis on near-wake flows of space transportation systems. PhD thesis, Rheinisch-Westfälische Technische Hochschule Aachen (2019)

16. Kirchheck, D., Saile, D., Gülhan, A.: Spectral analysis of rocket wake flow-jet interaction by means of high-speed schlieren imaging. In: 8th European conference for aeronautics and space sciences (EUCASS), Madrid, Spain, 1-4 July 2019

17. Scippa, S., Pascal, P., Zanier, F.: Ariane 5-MPS-chamber pressure oscillations full scale firing results: analysis and further studies. In: 30th Joint propulsion conference and exhibit, p. 3068 (1994)

18. Hermsen, R.: Aluminum oxide particle size for solid rocket motor performance prediction. J. Spacecr. Rockets 18(6), 483490 (1981)

19. Kulkarni, P., Baron, P.A., Willeke, K.: Aerosol measurement: principles, techniques, and applications. John Wiley \& Sons, Hoboken (2011)

20. Maggi, F., Carlotti, S., Galfetti, Saile, D., Gülhan, A., Liljedahl, M., Langener, T., van den Eynde, J.: Determining the particles size in solid rocket motor plume. In: International conference on flight vehicles, aerothermodynamics and re-entry missions and engineering (FAR) (2019)

21. Balakumar, B.J., Adrian, R.J.: Particle-image velocimetry measurement in the exhaust of a solid rocket motor. Exp. Fluids 36(1), 166-175 (2004). https://doi.org/10.1007/s00348-003-0692-z

22. Schodl, R.: Laser-two-focus velocimetry. In: Advanced instrumentation for aero engine components. In: AGARD-CP-399, paper 7, Philadelphia (1986)

23. Schodl, R., Förster, W.: A multi colour fiber optic laser two focus velocimeter for 3-dimensional flow analysis. In: 24th Joint propulsion conference, p. 3034 (1988)

24. Schodl, R., Förster, W., Beversdorff, M.: Neue Entwicklungen beim L2F-Verfahren. Berichte aus der Lasermeßtechnik "Lasermethoden in der Strömungsmeßtechnik". In: Leder, A. (Hrsg.), Verlag Shaker (1995)

25. Förster, W.: Laser-2-focus data analysis using a nonlinear regression model. In: ICIASF'95 record, international congress on instrumentation in aerospace simulation facilities, IEEE, pp. 22-1 (1995)

26. Ardey, S., Fottner, L., Beversdorff, M., Weyer, H.: Laser-2-focus measurements on a turbine cascade with leading edge film cooling. In: AGARD conference proceedings, AGARD, pp. 12-1 (1998)

27. Beversdorff, M., Matziol, L., Blaha, C.: Application of 3D-laser two focus velocimetry in turbomachine investigations. In: AGARD conference proceedings, AGARD, pp. 13-1 (1998)

28. Förster, W., Karpinsky, G., Krain, H., Röhle, I., Schodl, R.: 3-Component doppler laser-two-focus velocimetry applied to a transonic centrifugal compressor. In: Laser techniques for fluid mechanics, Springer, pp. 55-74 (2002)

29. n.a.: TSI Incorporated, diluter, model 3302A, operation and service manual, P/N 1933786, Revision E, June 2015. Tech. rep., TSI Incorporated (2015)

30. n.a.: TSI Incorporated, aerodynamic particle sizer, model 3321. Theory of operation. Tech. rep., TSI Incorporated (2012)

31. n.a.: TSI Incorporated, aerodynamic particle sizer, model 3321. High-resolution aerodynamic sizing plus light-scattering intensity. Tech. rep., TSI Incorporated (2017)

32. Carlotti, S., Maggi, F., Ferreri, A., Galfetti, L., Bisin, R., Saile, D., Gülhan, A., Groll, C., Langener, T.: Development of an intrusive technique for particles collection in rockets plume. Acta Astronaut. 158, 361-374 (2019). https://doi.org/10.1016/j.actaa stro.2018.06.030. http://www.sciencedirect.com/science/article/ pii/S0094576518303126

33. Carlotti, S., Maggi, F., Dossi, S., Bisin, R., Galfetti, L., Saile, D., Gülhan, A., Groll, C., Langener, T.: Overview of a supersonic probe for solid propellant rocket CCP collection. (2018). https:// doi.org/10.2514/6.2018-4882

34. Maggi, F., Bisin, R., Ferreri, A., Carlotti, S., Galfetti, L., Groll, C., Langener, T.: et al. Development of a probe for particle collection in high-temperature, supersonic flow: application of Quasi-1D engineering model and 2D axisymmetric CFD. In: 7th European conference for aeronautics and space sciences, pp. 3-7 (2017)

35. Carlotti, S., Ferreri, A., Bisin, R., Maggi, F., Galfetti, L., Saile, D., Gülhan, A., Langener, T.: Development of a probe for particle collection in high-temperature, supersonic flow: conceptual and detailed design. In: 7 th European conference for aerospace sciences (2017)

36. Maggi, F., Carlotti, S., Galfetti, Saile, D., Gülhan, A., Liljedahl, M., van den Eynde, J., Langener, T.: Particle size in SRM plume: assessment of collection method. In: 8th European conference for aeronautics and aerospace sciences (EUCASS) (2019)

Publisher's Note Springer Nature remains neutral with regard to jurisdictional claims in published maps and institutional affiliations. 